I+I I

\title{
BEST PRACTICES
}

Treatment and Rehabilitation for Driving While Impaired Offenders 



\section{BEST PRACTICES}

Treatment and Rehabilitation for Driving While Impaired Offenders 
Our mission is to help the people of Canada maintain and improve their health.

Health Canada

Published by authority of the Minister of Health

Également disponible en français sous le titre

Meilleures pratiques - Traitement et réadaptation des contrevenants

dans les cas de conduite avec facultés affaiblies

This publication can be made available (in/on computer diskette/large print/audio-cassette/braille) upon request.

For additional copies, please contact:

Publications

Health Canada

Ottawa, Ontario

K1A 0K9

Tel.: (613) 954-5995

Fax: (613) 941-5366

This publication is also available on the internet at the following address: www.healthcanada.ca

(C) Her Majesty the Queen in Right of Canada, 2004

Cat. H46-2/04-321E

ISBN 0-662-37448-7 


\section{Acknowledgements}

Health Canada would like to thank the technical team for this project that was led by Alan C. Ogborne, Canadian Centre on Substance Abuse (CCSA) and comprised of: Virginia Carver, private consultant; Robert Mann, Centre for Addiction and Mental Health; and Douglas J. Beirness, Traffic Injury Research Foundation. Various other CCSA staff supported this project: Gilles Strasbourg conducted the French interviews; Nina Frey and Manon Blouin conducted document search and acquisition respectively; Gilles Strasbourg and Richard Garlick edited the French and English reports respectively; Susan Rosidi oversaw the development of the inventory of driving while impaired (DWI) programs; and Gary Roberts managed the overall project. Appreciation is expressed to the Federal/Provincial/Territorial Working Group on Accountability and Evaluation Framework and Research Agenda (ADTR Working Group) for their support and guidance in developing this project, and the key informants for generously giving their time. 



\section{Table of Contents}

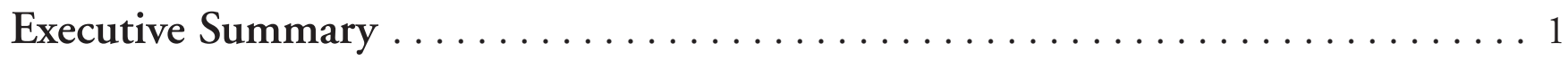

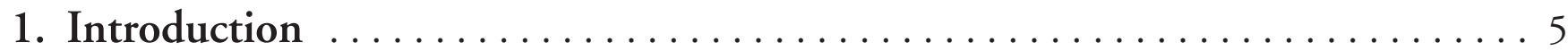

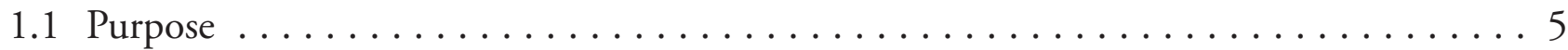

1.2 Study parameters and definitions $\ldots \ldots \ldots \ldots \ldots \ldots \ldots \ldots \ldots \ldots \ldots \ldots \ldots \ldots$

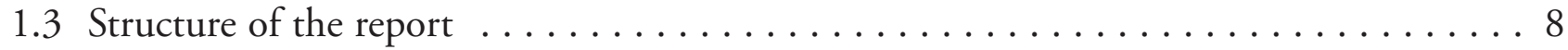

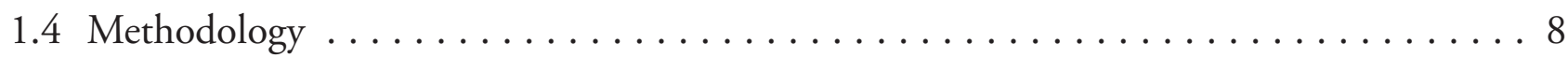

1.4 .1 Literature review $\ldots \ldots \ldots \ldots \ldots \ldots \ldots \ldots \ldots \ldots \ldots \ldots \ldots \ldots$

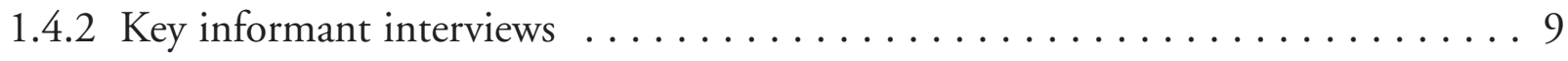

1.4 .3 Inventory of Canadian DWI programs $\ldots \ldots \ldots \ldots \ldots \ldots \ldots \ldots$

2. Overview of Impaired Driving in Canada $\ldots \ldots \ldots \ldots \ldots \ldots \ldots \ldots \ldots \ldots \ldots$

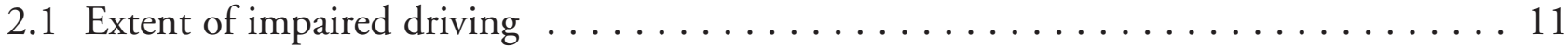

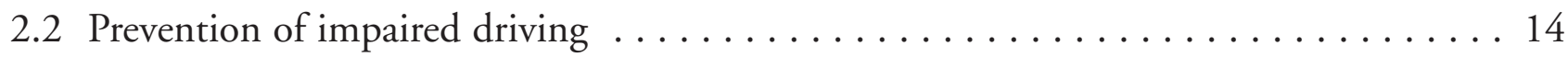

2.3 Regulatory and legal context of impaired driving $\ldots \ldots \ldots \ldots \ldots \ldots \ldots \ldots \ldots \ldots$

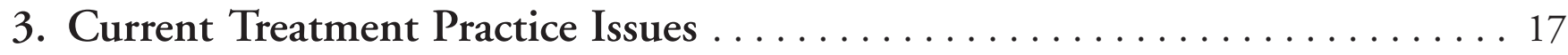

3.1 Effectiveness of educational or therapeutic interventions for DWI offenders . . . . . 17

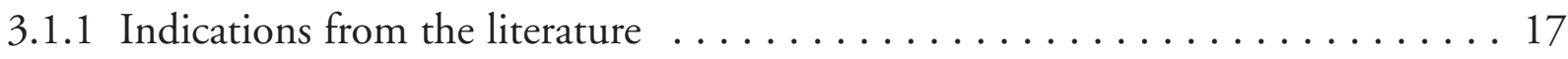

3.1 .2 Key informant interviews $\ldots \ldots \ldots \ldots \ldots \ldots \ldots \ldots \ldots \ldots \ldots \ldots \ldots \ldots \ldots$

3.1 .3 Best practices ................................... 31

3.2 Effectiveness of different types of treatment interventions for different types

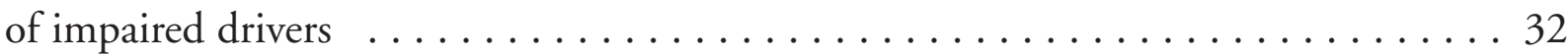

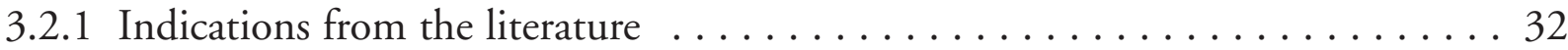

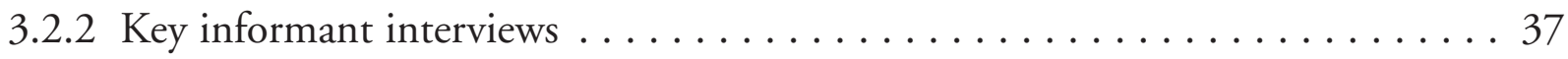

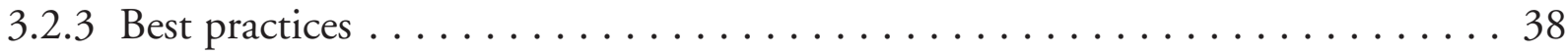


3.3 Identifying impaired drivers who may benefit from particular levels of substance abuse education or treatment . . . . . . . . . . . . . . . . . . . . . 39

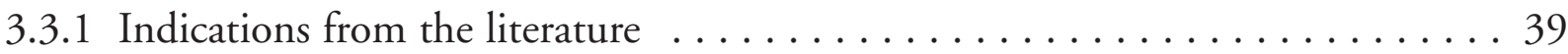

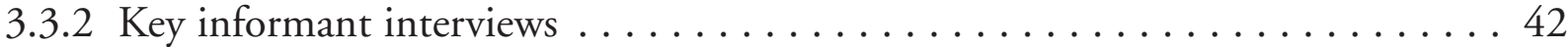

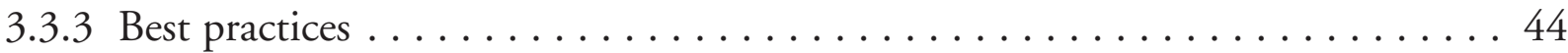

3.4 Effectiveness of programs that combine treatment and rehabilitation with licence suspension or other methods for limiting driving opportunities . . . . . . 45

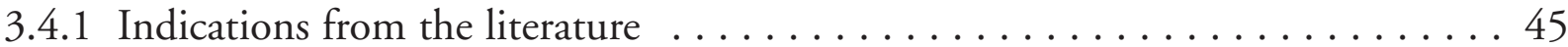

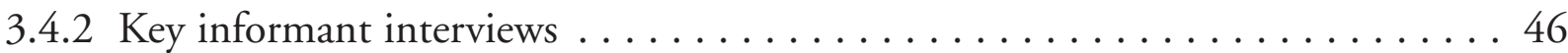

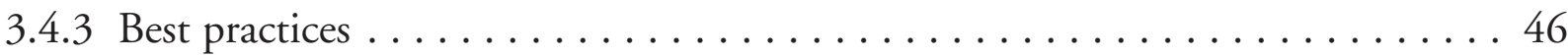

3.5 Interventions that target impaired drivers who are apprehended but not

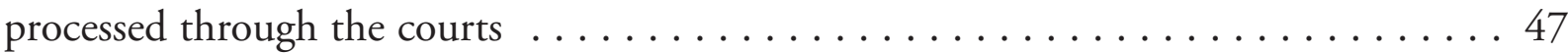

3.5.1 Indications from the literature $\ldots \ldots \ldots \ldots \ldots \ldots \ldots \ldots \ldots \ldots \ldots \ldots \ldots \ldots$

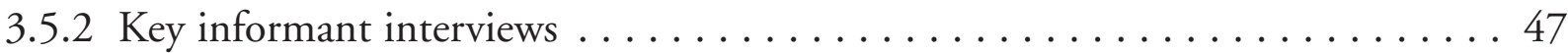

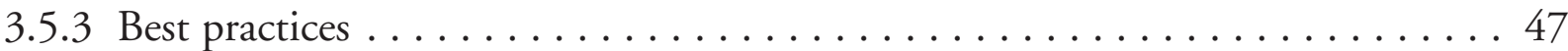

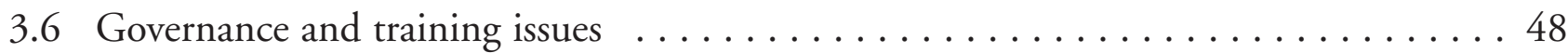

3.6.1 Indications from the literature $\ldots \ldots \ldots \ldots \ldots \ldots \ldots \ldots \ldots \ldots$

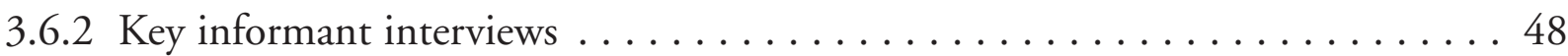

3.6 .3 Best practices ............................... 49

3.7 Relationships between DWI programs and licensing authorities . . . . . . . 50

3.7.1 Indications from the literature $\ldots \ldots \ldots \ldots \ldots \ldots \ldots \ldots \ldots \ldots \ldots \ldots \ldots \ldots$

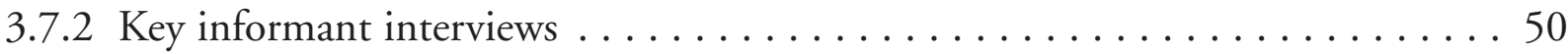

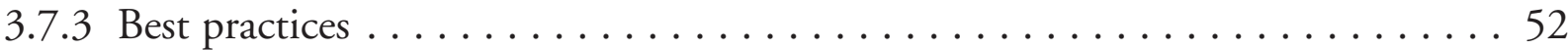

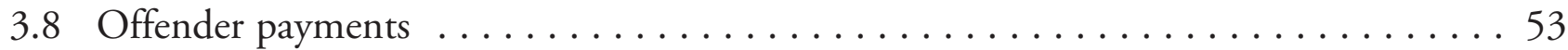

3.8.1 Indications from the literature $\ldots \ldots \ldots \ldots \ldots \ldots \ldots \ldots \ldots \ldots \ldots \ldots \ldots \ldots \ldots$

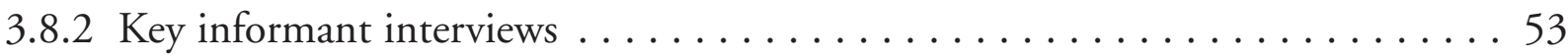

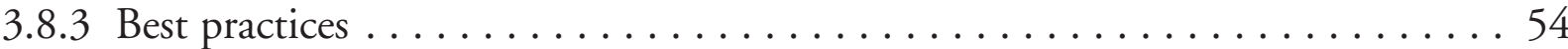




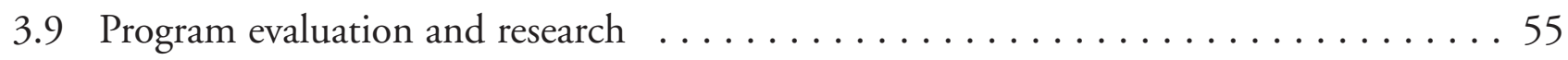

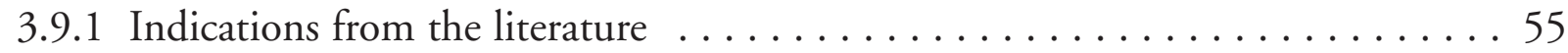

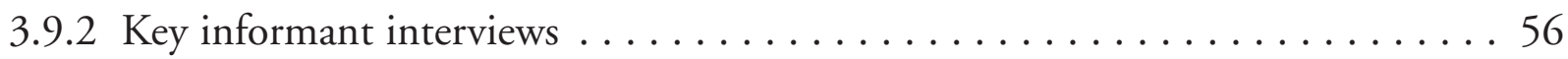

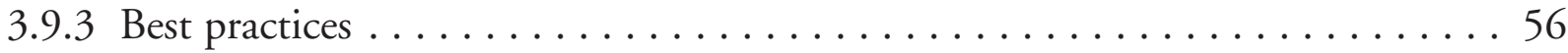

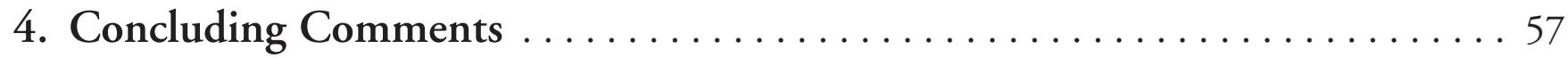

5. Best Practice Statements . . . . . . . . . . . . . . . . . . . . . . 59

6. Inventory of Canadian DWI Programs .................... 61

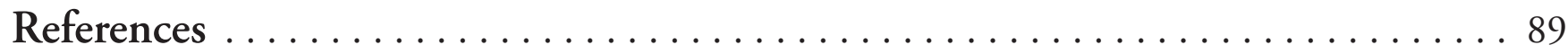

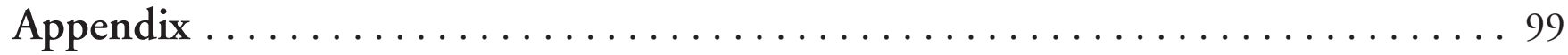

Appendix A: Rating Scale for Recent Studies _. . . . . . . . . . . . . . . . . . 99

\section{List of Figures and Tables}

Figure 1: Number and Rate of Persons Charged with an Impaired Driving Offence . . . . . 12

Figure 2: Percent of Fatally Injured Drivers Tested Positive for Alcohol . . . . . . . . . 13

Table 1: Recent Control or Comparison Group Studies of the Effectiveness of Education and Treatment for DWI Offenders $\ldots \ldots \ldots \ldots \ldots \ldots \ldots \ldots$

Table 2: Selected Characteristics of Commonly Used Questionnaires and Inventories for Identifying or Assessing DWI Offenders with Alcohol

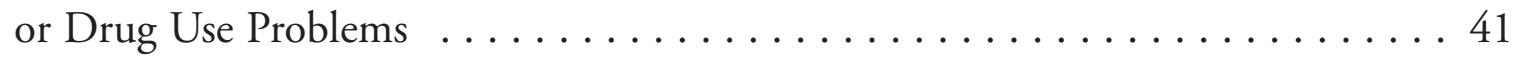





\section{Executive Summary}

The aim of this report is to bring together current knowledge on the planning and delivery of driving while impaired (DWI) remedial programs (i.e. education programs and treatment and rehabilitation programs).

Although the magnitude of the drinking and driving problem in Canada has declined over the past two decades, it remains a significant cause of mortality and morbidity in this country. Less is known about the impact of driving impairment due to other drug use, alone or in combination with alcohol, but there are indications that this is also an issue.

It is widely acknowledged that successes in reducing drinking and driving in this country have been the result of a broad and sustained mix of measures by governments and non-government groups. DWI remedial programs include both educational and treatment interventions, and are an important part of this mix, as are effective public awareness and prevention programs, comprehensive roadside detection and meaningful sanctions.

There is now a reasonably extensive literature concerning remedial programs for impaired driving offenders and good scientific evidence for their general effectiveness. The research reviewed and the experts consulted in the preparation of this report point to a number of practices that contribute to effectiveness; where the evidence warrants, these practices have been identified as best practices, and are as follows:

\section{Remedial education and treatment programs:}

1. Remedial programs should occupy an integral place in a comprehensive impaired driving countermeasure program. Participation in such programs should be a condition of licence reinstatement for all persons convicted of an impaired driving offence.

2. Remedial programs should also be an integral part of comprehensive efforts to reduce driving while impaired by drugs other than alcohol. Participation in such programs should be a condition of licence reinstatement for all persons convicted of a drug-related driving offence.

\section{Different types of remedial interventions for different types of DWI offenders:}

3. Comprehensive remedial programs for convicted impaired drivers should incorporate at least two levels of intervention for individuals with differing levels of substance use and related problems. 
4. All programs for convicted DWI offenders should incorporate both educational and therapeutic activities, regardless of program length.

5. Mandatory clinical follow-up after licence reinstatement should be required for all DWI offenders sent to remedial programs.

\section{Identification issues:}

6. All convicted DWI offenders should complete a screening/assessment process to inform decisions about the most appropriate level or type of intervention.

7. Instruments that have been shown to be of value in assessing alcohol and drug use problems and recidivism risk should form part of the screening procedure. The performance of these instruments should be monitored on an ongoing basis.

\section{Programs that combine treatment with other measures:}

8. Remedial programs should supplement, not replace, licensing actions.

\section{When DWI offenders are not processed through the courts:}

9. Individuals who receive pre-conviction roadside suspensions for impaired driving should be considered for referral to assessment and participation in remedial programs.

\section{Governance and training issues:}

10. Remedial programs should be located in an environment in which a behavioural health perspective and treatment orientation are well established and can be maintained.

11. Those providing remedial services to DWI offenders should be trained in substance use issues, and in adult education (particularly those delivering educational interventions) and group facilitation (particularly those delivering more therapeutic interventions).

12. Those providing remedial measures programs to convicted impaired drivers should be supported in accessing provincial or national training opportunities on an annual or biennial basis.

\section{Relationships between DWI programs and licensing authorities:}

13. Remedial programs should be operated using an administrative model, where program completion is a requirement for relicensing. 
14. Remedial programs should be operated by an agency other than the licensing authorities.

15. There is a need for formal and clear mechanisms for coordination and collaboration between licensing authorities and remedial programs to ensure reciprocal exchange of information to serve the best interests of clients and the public.

\section{Payment structures:}

16. Measures should be taken to reduce the financial burden for offenders, particularly those who are assigned to more expensive program options. This could include applying a single blended fee for all clients, or providing some form of financial assistance for low-income clients.

\section{Program evaluation and research:}

17. Evaluation should be an integral part of any remedial measures program.

18. Program evaluation and research costs should be built into program budgets.

19. More emphasis should be placed on quality assurance, and studies of the costeffectiveness of programs and their component parts.

This study has also pointed to gaps in current processes, knowledge and research that need to be explored, including but not limited to: 1) whether programs should be gender specific or age specific; 2) how best to serve Canada's ethnoculturally diverse populations; 3) which screening tools may be superior in identifying levels of substance use problems; 4) how to respond to the needs of those convicted of drug-impaired driving; 5) how to promote high standards of effective and efficient programming and program evaluation across Canada. 



\section{Introduction}

\subsection{Purpose}

In most industrialized countries, impaired driving is one of the most common crimes and a significant cause of alcohol- and drug-related mortality and morbidity. Most countries, including Canada, have therefore introduced measures to prevent impaired driving and to punish offenders. Many countries have also developed programs to educate, treat and/or rehabilitate people charged or convicted for driving while impaired (DWI) by alcohol and/or other drugs.

There is now a reasonably extensive literature concerning education, and treatment and rehabilitation programs for impaired driving offenders and also good scientific evidence for their effectiveness. The aim of this report is to bring together current knowledge on the planning and delivery of DWI education, and treatment and rehabilitation programs, particularly pertaining to the following issues:

- overall effectiveness of education and treatment programs for impaired drivers;

- effectiveness of different types of such remedial interventions for different types of impaired drivers;

\section{KEY POINTS}

- This study focusses on both educational and therapeutic remedial programs for people charged with or convicted of alcohol- and/or drug-related driving offences.

- Specific interventions of interest include 1) education typical of specialized DWI programs, and 2) interventions similar to those found in general addiction treatment programs. Both emphasize the importance of separating drinking/substance use from driving.

- identifying impaired drivers who may benefit from substance abuse education or treatment;

- effectiveness of programs that combine treatment and rehabilitation with licence suspension or other methods for limiting driving opportunities;

- need for interventions that target impaired drivers who are apprehended but not processed through the courts;

- DWI program governance and provider training issues;

- relationships between remedial programs and licensing authorities; 
- offender payments for services; and

- program evaluation and research.

Beyond these main questions, the research team was also asked to give attention to current knowledge on remedial programs for drivers impaired by drugs other than alcohol, and to be alert to issues of gender, ethnicity, place of residence (rural vs. urban), and clinician liability during the research.

The project was initiated by Health Canada as part of a research agenda developed by the Federal/Provincial/Territorial Working Group on Accountability and Evaluation Framework and Research Agenda (ADTR Working Group). Part of the mandate of the working group is to oversee the development and implementation of research studies that contribute to innovative substance abuse treatment and rehabilitation programs by identifying best practices, evaluating model treatment and rehabilitation programs, and identifying emerging issues. The knowledge is then disseminated across the country.
This project builds on a series of best practices publications including: Best Practices Substance Abuse Treatment and Rehabilitation (Health Canada, 1999); Best Practices - Fetal Alcohol Syndrome/Fetal Alcohol Effects and the Effects of Other Substance Use During Pregnancy (Health Canada, 2001a); Best Practices Treatment and Rehabilitation for Women with Substance Use Problems (Health Canada, 2001b); Best Practices - Treatment and Rehabilitation for Youth with Substance Use Problems (Health Canada, 2001c); Best Practices - Concurrent Mental Health and Substance Use Disorders (Health Canada, 2001d); Best Practices - Methadone Maintenance Treatment (Health Canada, 2002a); and Best Practices - Treatment and Rehabilitation for Seniors with Substance Use Problems (Health Canada, 2002b)

\subsection{Study parameters and definitions}

Following initial discussions with members of the ADTR Working Group, it was determined that the study would focus on educational and therapeutic remedial programs $s^{1}$ for people charged with or convicted of alcohol- and/or drug-related driving offences. Efforts were also made to identify knowledge on the identification and treatment of substance use problems ${ }^{2}$ among those charged with other traffic offences (e.g. dangerous driving, leaving the scene of an accident), and impaired drivers who are apprehended by the police, but not processed

\footnotetext{
${ }^{1}$ The term "remedial programs" in the context of this report, refers to education and therapeutic programs for DWI offenders.

${ }^{2}$ The term "substance use problems" is used to cover both substance abuse and substance dependence, as defined by the American Psychiatric Association in the Diagnostic and Statistical Manual (DSM)-IV (1994)
} 
through the justice system. These latter types of offenders are given roadside or administrative licence suspensions, but are not subsequently prosecuted.

Interventions of concern were those typically used in specialized remedial programs for DWI offenders and those used in programs indicated in the 1998 Canada's Drug Strategy planning document, namely:

... detoxification services, early identification and intervention, assessment and referral, basic counselling and case management, therapeutic intervention, and aftercare and clinical follow-up. ... offered on an outpatient, day-patient or in-patient basis including short-term and long-term residential care.

(Health Canada, 1998, p. 9)

Specific interventions of interest included education typical of specialized DWI programs that focus on substance use and driving, and the importance of separating the two, as well as interventions similar to those found in general addiction treatment programs in Canada (e.g. counselling, self-help, cognitive-behaviour therapy, family therapy, guided self-change), but also have a focus on separating drinking and driving.

Some reports of interventions that specifically target impaired drivers in emergency rooms or other medical settings were found (e.g. Gentilello et al., 1999; Monti et al., 1999). However, these were considered to be beyond the scope of this project, because they are interventions with impaired drivers who have not been apprehended by the police. Victim impact panels are a common, yet largely ineffective, form of remediation that were considered beyond the scope of this report (C'de Baca et al., 2001; Polacsek et al., 2001; Shinar and Compton, 1995).

Other interventions, such as mandatory use of ignition interlock devices, fines and electronically monitored home confinement, were considered beyond the present scope of this report. However, as will be seen, there is evidence that education and treatment programs are most effective when combined with licence suspension and other measures, such as impounding offenders' vehicles or licence plates, installing ignition interlocks, or requiring electronic home monitoring or house arrest.

The definition of best practice as it relates to program delivery in the health field has been approached with varying degrees of rigour. For the purposes of this project, best practices are emerging guidelines, gleaned from key expert perspectives and supported by the literature, on the approaches and elements of treatment that appear to result in successful treatment outcomes. Given this definition, best practices are recommendations that may evolve, based on ongoing key expert experience, judgment, perspective and continued research. 


\subsection{Structure of the report}

The report first provides a general overview of the impaired driving situation in Canada. The main body of the report is structured around the nine main issues identified in the introduction; current knowledge drawn from the literature and key informants is summarized in each section,

\subsection{Methodology}

For the best practices, two sources of information were drawn upon:

- a review of published and unpublished research reports on DWI treatment and rehabilitation; and

- interviews with experts in the field of DWI program development and delivery.

\subsubsection{Literature review}

The primary sources used to identify research reports were:

- Alcohol and Alcohol Problems Science Database (ETOH) of the US National Institute on Drug Abuse (NIDA);

- the web site of the US National Commission Against Drunk Driving (www.ncadd.com);

- a recent review of DWI literature (Beirness, Mayhew and Simpson, 1997);

- MEDLINE (Database of the National Library of Medicine, National Institutes of Health, U.S.); and when the level of knowledge warrants, best practice statements are presented. Gender, ethnicity, place of residence (rural vs. urban) and other issues are variously addressed under the main topic headings. Concluding the report is an inventory of Canadian DWI programs.

For the Inventory of Canadian DWI Programs (see Section 6), information was gathered through the administration of a written survey completed by persons responsible for provincial/ territorial impaired driving programs in Canada.

- CANBASE (the database of Canadian addiction library holdings);

- CCSADOCS (the database of holdings of the Canadian Centre on Substance Abuse); and

- reports identified by members of the steering committee.

Priority for review was given to reports of controlled studies pertaining to the issues of concern. A number of reports or publications by expert panels or internationally respected authorities were examined for knowledge 
pertaining to the aims of this report. These are referenced in various sections that follow. A scale (see Appendix A) was developed to rate

\subsubsection{Key informant interviews}

The project steering committee nominated 12 key experts (e.g. directors, managers and medical consultants for DWI programs) on the basis of their expertise in various aspects of DWI remedial programming, and on the basis of regional representation. The key experts were contacted by the project team to solicit their participation in a telephone interview of approximately 90 minutes. A standard interview guide was used during the interview, but with particular emphasis given to the key informant's specific area of expertise.

In the interviews, key informants were asked for their advice on the following issues drawn from the main research questions: screening for each study on the quality of the research and strength of outcomes. The ratings are presented in Table 2. substance use problems; assessment and treatment assignment; effectiveness of educational and therapeutic interventions; administrative or judicial compliance mechanisms; effectiveness of programs that combine treatment with licence suspension or some other method of limiting driving opportunities; case monitoring, evaluation and research; provider training; recovery of costs for education/treatment programs; relationships between education or treatment services and motor vehicle registration departments; and programming for youth DWI offenders. Key informants were also asked about any recent developments in DWI remedial measures programming in their jurisdiction.

\subsubsection{Inventory of Canadian DWI programs}

Program inventories from Bierness, Simpson and Desmond (1994) and Stoduto et al. (1998) were used to identify respondents for a survey of Canadian DWI programs. Key personnel were contacted in the fall of 2002 and asked to provide a profile of their program by completing a survey questionnaire. In many cases, follow-up phone calls were made to clarify or elaborate on information given. 



\section{Overview of Impaired Driving in Canada}

\subsection{Extent of impaired driving}

Driving while impaired by alcohol and/or other substances continues to be a major cause of vehicle crashes, injuries and deaths in Canada. One indicator of the magnitude of the impaired driving problem in Canada that is of particular relevance to the present project is the number of persons charged by the police with a Criminal Code impaired driving offence. Figure 1 presents the number and rate (per 10,000 licensed drivers) of impaired driving charges in Canada from 1974 through 2001. The total number of persons charged with impaired driving reached a peak of 162,048 in 1981. The number of impaired driving charges laid in a given year is, of course, partly a reflection of the level of enforcement activity.

However, it is generally agreed that the unprecedented reductions in impaired driving during the 1980s reflected the many new prevention and awareness programs, policies and activities that were developed during this period. The absolute number of charges decreased dramatically, falling to a low of 69,192 in 2000 - a decrease of 57\%; in the most recent year for which data are available, the number of persons charged with an impaired driving offence increased slightly to 71,087 (Canadian Centre for Justice Statistics, 2002).

\section{KEY POINTS}

- Driving while impaired by alcohol and/or other substances continues to be a major cause of vehicle crashes, injuries and deaths in Canada.

- The unprecedented reductions in impaired driving during the 1980s reflected the many new prevention and awareness programs, policies and activities that were developed during this period.

- In the decade between 1981 and 1990, the percent of fatally injured drinking drivers decreased from $62 \%$ to $45 \%$.

- In 2000, 35.6\% of drivers killed in crashes tested positive for alcohol.

- Less is known about the prevalence of driving while impaired by drugs, however research provides evidence of increases in collision risk.

- Laws making it an offence to drive while impaired by alcohol have been in Canada's Criminal Code for many years. In 1969, the impaired driving law was supplemented by a per se law, which made it an offence to drive with a Blood Alcohol Content (BAC) over $80 \mathrm{mg} \%$.

- Canada’s Criminal Code makes it an offence, with penalties equivalent to those for driving with a BAC over $80 \mathrm{mg} \%$, to refuse to provide a breath test.

- As well, most provinces have administrative sanctions that apply to drivers with BAC levels lower than $80 \mathrm{mg} \%$ - usually at $50 \mathrm{mg} \%$. 


\section{Figure 1: Number and Rate* of Persons Charged with an Impaired Driving Offence (Canada 1974-2001)}

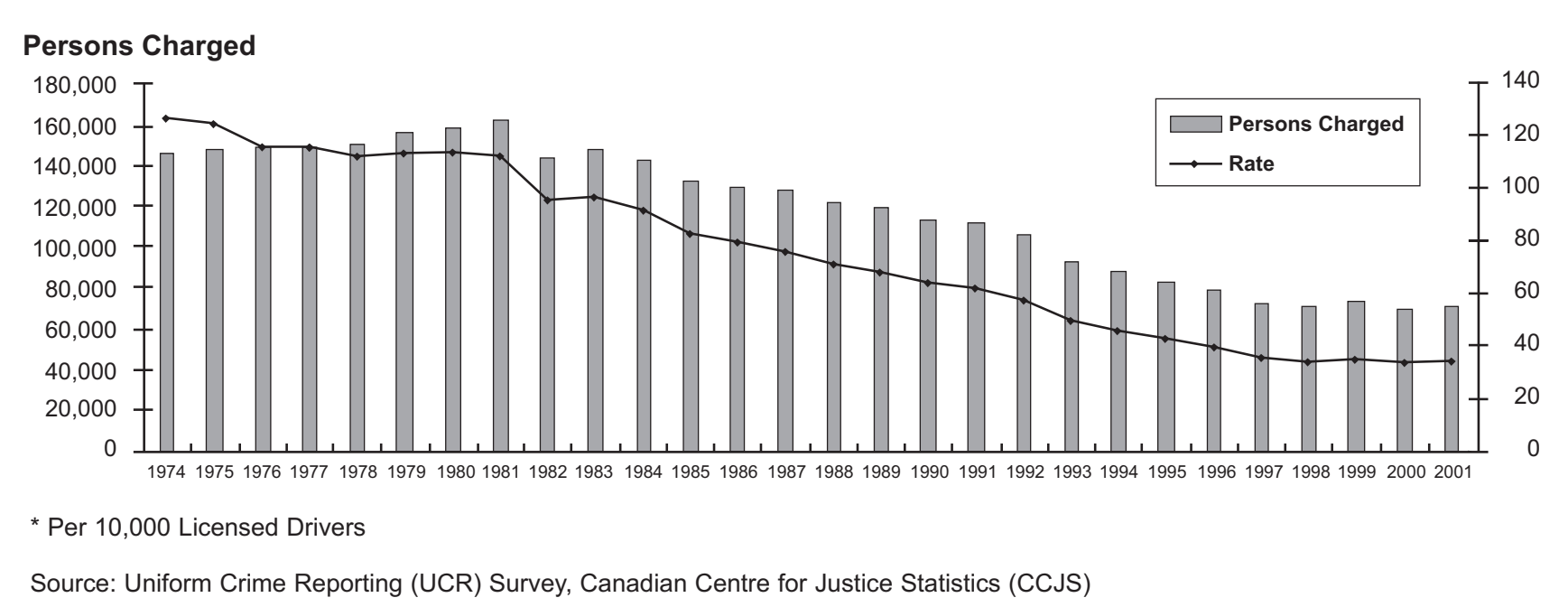

A commonly used indicator of the magnitude of the DWI problem is the percent of fatally injured drivers who test positive for the presence of alcohol. Figure 2 presents this indicator for Canada from 1973 through 2000. It is evident in this figure that during the 1970s, there was very little change in the magnitude of the problem. In fact, this index of the problem reached a peak in 1981 when $62 \%$ of fatally injured drivers were found to have consumed alcohol. However, in the decade between 1981 and 1990, the percent of fatally injured drinking drivers decreased from $62 \%$ to $45 \%$. The progress of the 1980s suffered a setback in the early part of the 1990s, but the downward trend has recently been re-established, albeit at a slower rate. In 2000, 35.6\% of drivers killed in crashes tested positive for alcohol. In this, the most recent year for which data are avail- able, it is estimated that 864 persons were killed in motor vehicle collisions involving a driver who had been drinking (Mayhew, Brown and Simpson, 2002).

Although these and other indicators of impaired driving are substantially lower than their equivalents in previous decades, impaired driving is still a major concern. Motor vehicle collisions (MVCs), many of which are caused by drinking drivers, are a serious health and safety issue in Canada. MVCs were the seventh leading cause of Potential Years of Life Lost (PYLLs) in 1997, and among children aged 0 to19 they were the third leading cause of PYLLs (National Cancer Institute of Canada, 2001). About one third of all deaths resulting from MVCs involve a drinking driver (Mayhew, Brown and Simpson, 2002). Alcohol-related 
motor vehicle crashes account for $13 \%$ of all alcohol-related hospitalizations and $12 \%$ of all alcohol-related days in hospital (Single et al., 1996). They also account for $22 \%$ of all alcohol-related deaths and 33\% of all alcoholrelated years of life lost (Single et al., 1996). Single et al. (1996) estimated that in 1992 alcohol-related collisions in Canada resulted in direct costs for damage of $\$ 482,800,000$.

Much less is known about the prevalence of driving while impaired by drugs other than alcohol, and the risks associated with this behaviour. Canadian and international research does provide evidence that cannabis, cocaine, possibly other illicit drugs such as hallucinogens, and some drugs used for therapeutic purposes, such as benzodiazepines, impair the skills necessary for safe driving and are associated with significant increases in collision risk (Dussault et al.,
2002; Macdonald et al., 2002). After alcohol, the drugs most often detected in seriously and fatally injured drivers are cannabis, benzodiazepines and stimulants (including cocaine) (Cimbura et al., 1990; Stoduto et al., 1993). Walsh and Mann (1999) reported that, in a representative sample of Ontario adult drivers, $1.9 \%$ said they had driven within an hour of smoking cannabis at least once in the previous 12 months and the proportion reporting driving after using cannabis was highest among younger respondents.

More recently, Adlaf, Mann and Paglia (2003) reported that, among Ontario high school students with a driver's licence, $19.3 \%$ reported driving after using cannabis at least once in the previous year. Research from Canada and elsewhere indicates that some psychoactive drugs normally used for therapeutic purposes have

\section{Figure 2: Percent of Fatally Injured Drivers Tested Positive for Alcohol: 1973-2000}

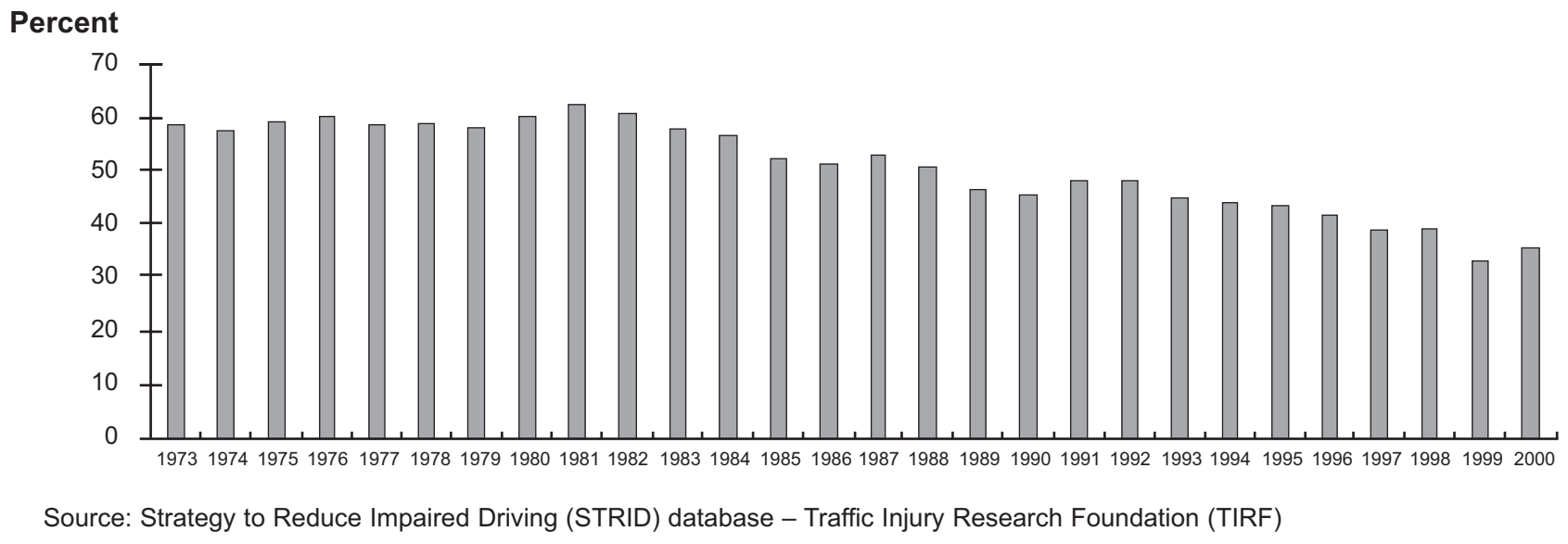


also been shown to be associated with increased collision risk (e.g. Hemmelgarn et al., 1997). Neutel (1995), in a Saskatchewan study, reported that the likelihood of a traffic injury increased significantly during the period after prescriptions for benzodiazepines were filled, in comparison with controls who did not receive a prescription for benzodiazepines. In a recent report of a random sample of Canadian drivers, $17.7 \%$ indicated that, during the past 12 months, they had driven within two hours of taking some type of drug that could affect one's ability to drive safely. The drugs most commonly used in this context were overthe-counter medications (15.9\%), prescription medications (2.3\%), cannabis (1.5\%) and other illegal drugs (.9\%) (Beirness et al., 2003).

\subsection{Prevention of impaired driving}

Clearly, successes in reducing drinking and driving in this country have not been the result of any single initiative; instead, they are the result of a broad and sustained mix of measures by governments and non-government groups over this period. Three main types of activities have been prominent among efforts to prevent impaired driving during the past 15 to 20 years: (1) primary prevention, which aims to educate the general public about the dangers of impaired driving; (2) secondary prevention, which increases the efficiency of law enforcement; and (3) tertiary prevention, which aims to reduce the risk of re-offending among those guilty of impaired driving, including educating offenders or treating them for a substance use problem. A major thrust in tertiary prevention has been to increase penalties for all types of impaired offenders and especially for repeat offenders.

Canada has a national Strategy to Reduce Impaired Driving (STRID). The STRID Task Force is under the auspices of the Canadian Council of Motor Transport Administrators (CCMTA). The CCMTA has adopted the
Road Safety Vision 2010 (Transport Canada, 2002), which is an enhanced plan to make Canada's roads the safest in the world. One target is to reduce morbidity and mortality from driving while impaired by $40 \%$ by the year 2010. The plan is supported by all levels of government, as well as by public and private sector stakeholders.

DWI offender education programs were initially developed in the 1960s when it first became apparent that many such offenders knew little about the effects of alcohol on driving performance and related issues, and had inappropriate attitudes to driving after drinking. These programs had mixed and often poor results when used as alternatives to legal sanctions and licence suspensions, without regard to individual differences in alcohol-related and other problems among those involved (Mann, 1992). However, further research and analysis indicated that, when combined with licence suspensions, education programs did reduce the risk of subsequent DWI offences among offenders who did not have significant alcohol use problems. These programs are thus supported by many 
jurisdictions and DWI offenders are often required to attend such programs in order to regain their drivers' licences.

In Canada, interest in the potential value of remedial programs for drinking-driving offenders dates back many years (e.g. Smart and Schmidt, 1961). The first specialized programs for impaired driving offenders were probably developed and implemented on a limited basis in the 1960s (Mann, 1992). Since then, programs have been developed and implemented in many parts of the country. The comprehensive province-wide program in Manitoba has served as a model for programs in other provinces.

Mandatory screening/assessment and educational or treatment intervention programs are in place in many provinces/territories and are recommended by the STRID 2010. These require the offender to go through a screening/ assessment process and/or to complete an educational or treatment intervention prior to licence reinstatement. In those jurisdictions with such programs, there are typically two or three levels of intervention. The first level-for first offenders or those considered to be low risk-is usually a brief educational session. The second level of intervention is for offenders at an early stage of a substance use problem or at higher risk because of their attitudes and behaviours regarding drinking and driving. It usually takes place over a more extended period of time and may involve a more comprehensive assessment, as well as an opportunity to work on strategies to address identified problem areas. The third level of intervention is for offenders assessed as having a serious substance use problem or dependency and usually involves a referral to a substance abuse treatment program. In those jurisdictions that have mandatory DWI programs, there is typically some cost-recovery for either the assessment alone or for the assessment and treatment.

\subsection{Regulatory and legal context of impaired driving}

Laws making it an offence to drive while impaired by alcohol have been in Canada's Criminal Code for many years. In 1969, the impaired driving law was supplemented by a per se law, which made it an offence to drive with a Blood Alcohol Content (BAC) over $80 \mathrm{mg} \%$. Per se laws had been introduced in Scandinavian countries and in Great Britain, where it was found that they greatly facilitated the processing of drinking-driving cases and resulted in significant reductions in collisions, injuries and fatalities (Mann et al., 2001; Ross,
1984). In addition, Canada’s Criminal Code makes it an offence, with penalties equivalent to those for driving with a $\mathrm{BAC}$ over $80 \mathrm{mg} \%$, to refuse to provide a breath test. The Criminal Code was revised in 1985, creating new offences for impaired driving causing bodily harm and impaired driving causing death. More recently, the Government of Canada increased the penalties in the Criminal Code for impaired driving, including a maximum penalty of life in prison for impaired driving causing death. 
All provinces and territories also use their authority under their respective highway traffic laws to impose administrative sanctions and measures that apply to drivers convicted of Criminal Code drinking-driving offences. These sanctions are independent of the Criminal Code and may include for example licence suspensions that exceed the prohibition time mandatory under the Criminal Code. These provincial and territorial sanctions and measures are invoked on conviction of a Criminal Code DWI offence.
As well, most provinces have the roadside licence suspension, an administrative sanction that applies to drivers with BAC levels lower than $80 \mathrm{mg} \%$ - usually at $50 \mathrm{mg} \%$. These roadside licence suspensions take effect immediately, rather than upon conviction of a Criminal Code DWI offence. Roadside licence suspensions are ordered at the roadside at the discretion of police officers and licences are suspended for 12 or 24 hours. Some provinces keep official records of these roadside licence suspensions. 


\section{Current Treatment Practice Issues}

\subsection{Effectiveness of Educational or Therapeutic Interventions for DWI Offenders}

\subsubsection{Indications from the literature}

To determine the effectiveness of any kind of education, treatment or rehabilitation program for DWI offenders, it is necessary to use a research design that controls for the influence of other, non-treatment factors such as motivation, problem severity and social resources. The optimal research design is one that involves subjects who are randomly assigned to the intervention of interest or to some alternative. Alternatives could include punishment, no education or treatment and/or different kinds of education or treatment. Most studies of education and treatment for impaired drivers have not used this kind of experimental design. This is because it is difficult to persuade the courts to randomly select convicted DWI offenders for punishment with or without some kind of treatment. However, there are some notable exceptions (see below).

A more common study design is the quasiexperiment where outcomes for those who receive the intervention of interest are compared with those for similar groups or

\section{KEY POINTS}

- Remedial programs for convicted DWI offenders have become increasingly used over the past decades.

- There is good empirical evidence that remedial programs can positively influence knowledge, beliefs, attitudes, alcohol use, recidivism, collisions and the health status of convicted DWI offenders.

- Based on a meta-analysis by Wells-Parker et al. (1995), treatment and rehabilitation had on average a small but positive influence $(7-9 \%$ reduction) on the incidence of recidivism and crashes, when compared with standard punitive sanctions without treatment.

- The Wells-Parker et al. (1995) meta-analysis also suggested that combined strategies were most effective for multiple, as well as first offenders.

- The literature search conducted for this project identified 11 reports of control or comparison group studies written since 1990 that aimed to assess the effects of education or treatment on DWI recidivism.

- No studies of the impact of a remedial program for individuals convicted of driving while impaired by drugs other than alcohol were located.

Key Points continues on page 18 
individuals who did not. The challenge for the researcher in these cases is to match individuals or groups on variables other than treatment that could influence their respective fates. Matching variables typically include age, gender, problem severity, and DWI arrest and conviction history. Sometimes this is done by finding control cases for each individual in the intervention group or by finding comparison groups whose overall characteristics are similar to those in the intervention group. Statistical methods can also be used to adjust for measured differences between those in the treatment and the comparison group(s). However, the results of quasi-experimental studies will be compromised if the groups studied differ on factors that are not measured or controlled (e.g. on levels of motivation for treatment, or exposure to criminal sanctions).

Other critical issues for the evaluation of interventions for DWI offenders include the selection of outcome measures and the followup interval. The most commonly used outcome measure is recidivism, as indicated by subsequent DWI arrests and convictions. This has the advantage of objectivity, but may be a poor indication of actual DWI behaviours because the risk of arrest for driving while impaired by alcohol or drugs is small even for repeat offenders. There is also an ethical concern for treatment providers in the use of post-treatment arrests as indicators of treatment outcome because the absence of an arrest does not necessarily reflect attainment of treatment goals. Thus, convicted DWI offenders who are not subsequently re-arrested for the same offence might have modified their driving behaviours but still have serious drinking or drug-use problems. These would be considered failures

\section{KEY POINTS (cont'd)}

- Studies that evaluate the effects of treatment for drug use problems on driving measures have begun to appear, and have found that significant post-treatment reductions in, for example, DWI convictions and total collisions, have been obtained. from a clinical perspective, but successes from a harm reduction or public safety perspective. This may not be important if treatments are principally intended to have harm reduction goals (i.e. no drinking and driving), but this has not generally been the case. DWI offenders are given treatment not only to prevent them from further driving when impaired by alcohol or drugs but also because they are believed to need help with their drinking or drug use.

The length of follow-up is also critical to the evaluation of education and treatment programs for DWI offenders because these programs are expected to have a lasting impact. The DWI research literature includes examples of follow-up studies over 10 years or more, but there are also studies with much shorter followup intervals and their results may not be valid over a longer term.

Many published and unpublished reports of studies use quasi-experimental or experimental designs to determine if specific kinds of education or treatment affect the subsequent behaviours of people who drink or take drugs, and drive. In most cases, these studies have compared those who received some type of education or treatment with those who did not. However, a few studies have compared different types of education or treatment. Generally, the main 
outcome of interest has been DWI recidivism as indicated by post-intervention arrests.

A large number of studies (194) published during or before 1990 were the subject of a meta-analysis by Wells-Parker et al. (1995). These studies all involved DWI offenders and had compared "remediation" (active probation, education, psychological treatments, victim impact panels and ignition interlocks ${ }^{3}$ ) to no remediation, or two or more forms of remediation. Many of those given education or treatment also received licensing penalties and sometimes these were more severe than those imposed on non-remediation groups. Eighteen of the studies compared two or more independent samples, thus providing a total of 212 discrete studies for analysis.

The studies varied greatly with respect to their methodological rigour and thus the degree of confidence that could be placed in the reported results and conclusions. Common problems included poor reporting of results, and inadequate description of the interventions and sanctions applied to the remediation and nonremediation groups. These problems were taken into account in the meta-analysis and, in general, studies that were methodologically strong showed remediations to have less effect than those that were methodologically weak.

The analysis did, however, indicate that, on average, treatment and rehabilitation had a small but positive influence (7-9\% reduction) on the incidence of alcohol-related driving recidivism and crashes, when compared with standard punitive sanctions without treatment.
The average in this case took account of all types of offenders and all types of rehabilitation and treatment for which data were available. This was consistent with the conclusions drawn for some earlier reviews of the published literature (Mann et al., 1983; McKnight and Voas, 1991), but at variance with reviews by Foon (1988) and the Institute of Medicine (1990), which concluded that remediation for DWI offenders had no measurable effects.

The Wells-Parker et al. (1995) meta-analysis also suggested that combined strategies (i.e. education plus psychotherapy, plus follow-up such as contact monitoring and aftercare) were most effective for multiple, as well as first offenders. However, "severe" or "high-problem" offenders (the definition of which varied across studies) showed smaller post-treatment reductions in drinking and driving than offenders with more moderate risk levels. It should be noted that some of these high-risk groups also tended to receive less effective interventions (e.g. mandatory Alcoholics Anonymous (AA) alone). Wells-Parker and colleagues have argued that these results demonstrate the need for further research, particularly on the benefits of matching different types of DWI offenders to different types of treatment.

The literature search conducted for this project identified 11 reports of control or comparison group studies written since 1990 (the cut-off year for studies in the Wells-Parker review) that aimed to assess the effects of education or treatment on DWI recidivism. These studies are summarized in Table 1 and further details are given below. Table 1 also includes scores

\footnotetext{
${ }^{3}$ As noted earlier, ignition interlocks are not otherwise considered in this report.
} 
assigned for methodological rigour using a scheme (Appendix A) based on a scale used by Wells-Parker et al. (1995). However, given our more modest objectives, studies are not discriminated to the same degree. The maximum score was 12 (most rigorous). Scores below 6 indicate serious limitations and the need for extreme caution in interpreting results. The main reasons for low ratings were: (1) lack of information on the interventions studied, and (2) uncontrolled biases associated with the selection of cases for education or treatment. Typically, the selection process for these studies involved self-selection and judgment calls by magistrates. Another limitation in some cases was the compounding of education or treatment with other benefits such as the avoidance of criminal conviction or jail.

Peck, Arstein-Kerslake and Helander (1994) reported an assessment of factors affecting recidivism in a group of convicted drinking drivers in California. The data for this analysis were obtained from data from two previously described randomized evaluations of the effects of remedial programs (Reis, 1982a,b), both of which found that assignment to remedial programs resulted in significant reductions in recidivism. Peck, Arstein-Kerslake and Helander (1994) combined the data from the two studies reported by Reis and used multivariate statistical methods to attempt to control for previous driving record, criminal record, age, marital status, occupation and attitudes at intake. Because the two studies involved substantial differences in offender groups, remedial interventions used, and locations in which the programs were offered (among other differences), the analyses reported by Peck Arnstein-Kerslake and Helander (1994) are most appropriately viewed as a comparison group design in which group equivalence on key variables is not always clear.

Offenders in this study $(\mathrm{N}=7,316)$ had been assigned to one of several first or repeat offender programs or to no-treatment control groups. The treatment options for first offenders were: (1) in-class education (four 2.5 hour sessions) or (2) home study. For repeat offenders, the treatment options were: (1) therapeutic counselling; (2) counselling plus anti-alcohol drug therapy; or (3) bi-weekly contacts without counselling or anti-alcohol drug therapy. The outcome measure was a composite measure unique to this study, which included reckless driving, accidents where the index case had been drinking and driving, late night accidents and DWI charges. While several demographic and driving-related measures were significant predictors of this composite measure of problem driving, participation in a remedial program was not.

Taxman and Piquere (1998) reported on a three-year follow-up of 3,671 convicted DWI offenders in Maryland who had received various dispositions from the courts. These are listed in Table 1 but the authors provide few details. However, they indicated that the education component was a state-certified program, and that treatment was mainly on an outpatient basis. Assignment to particular forms of punishment and/or treatment was at the discretion of the court and based on multiple factors.

A Cox proportional hazard model was used to identify variables that predicted recidivism over a three-year period. Offender variables used in this analysis were age, gender, first-time offender (yes/no), and number of prior traffic convictions. 


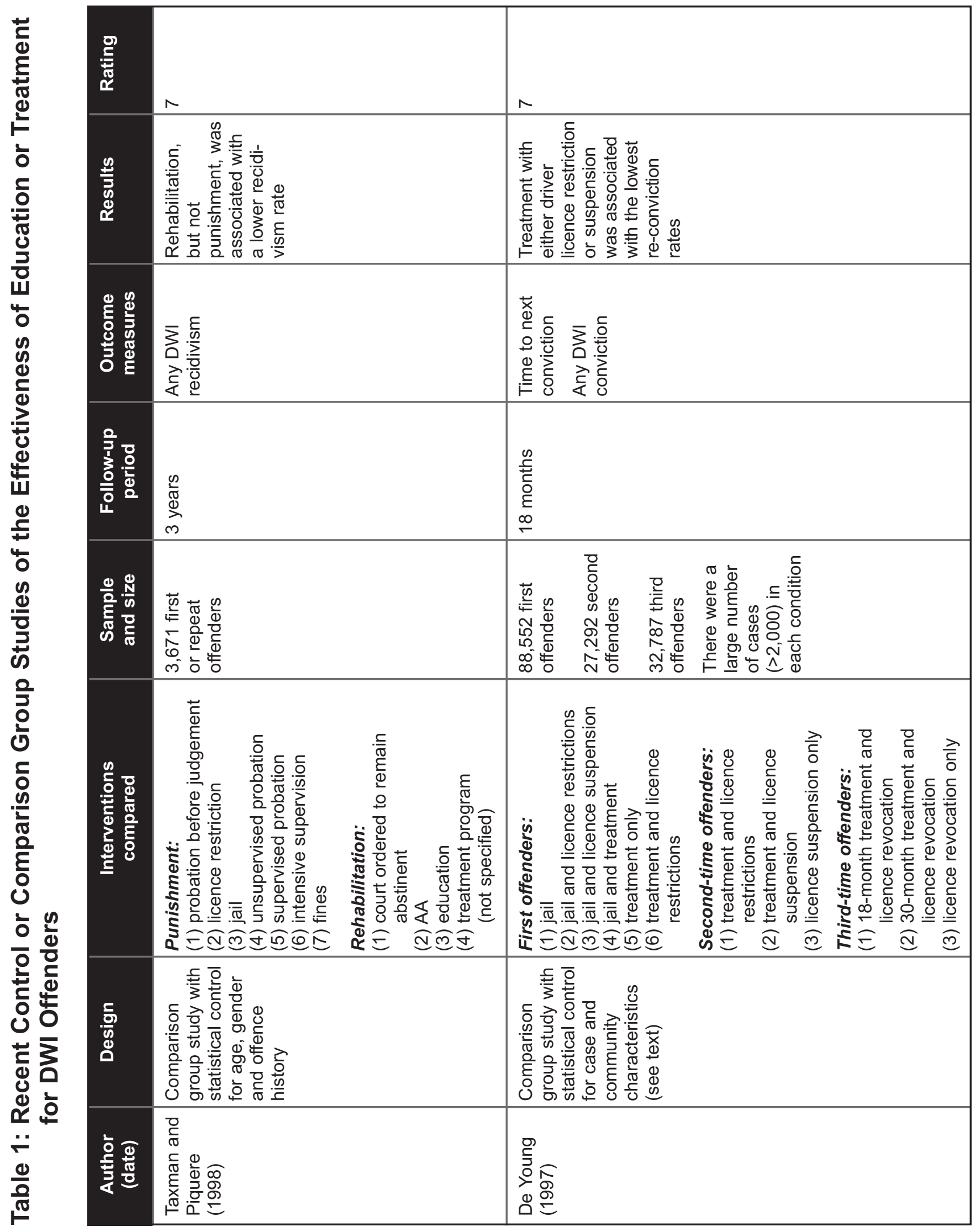




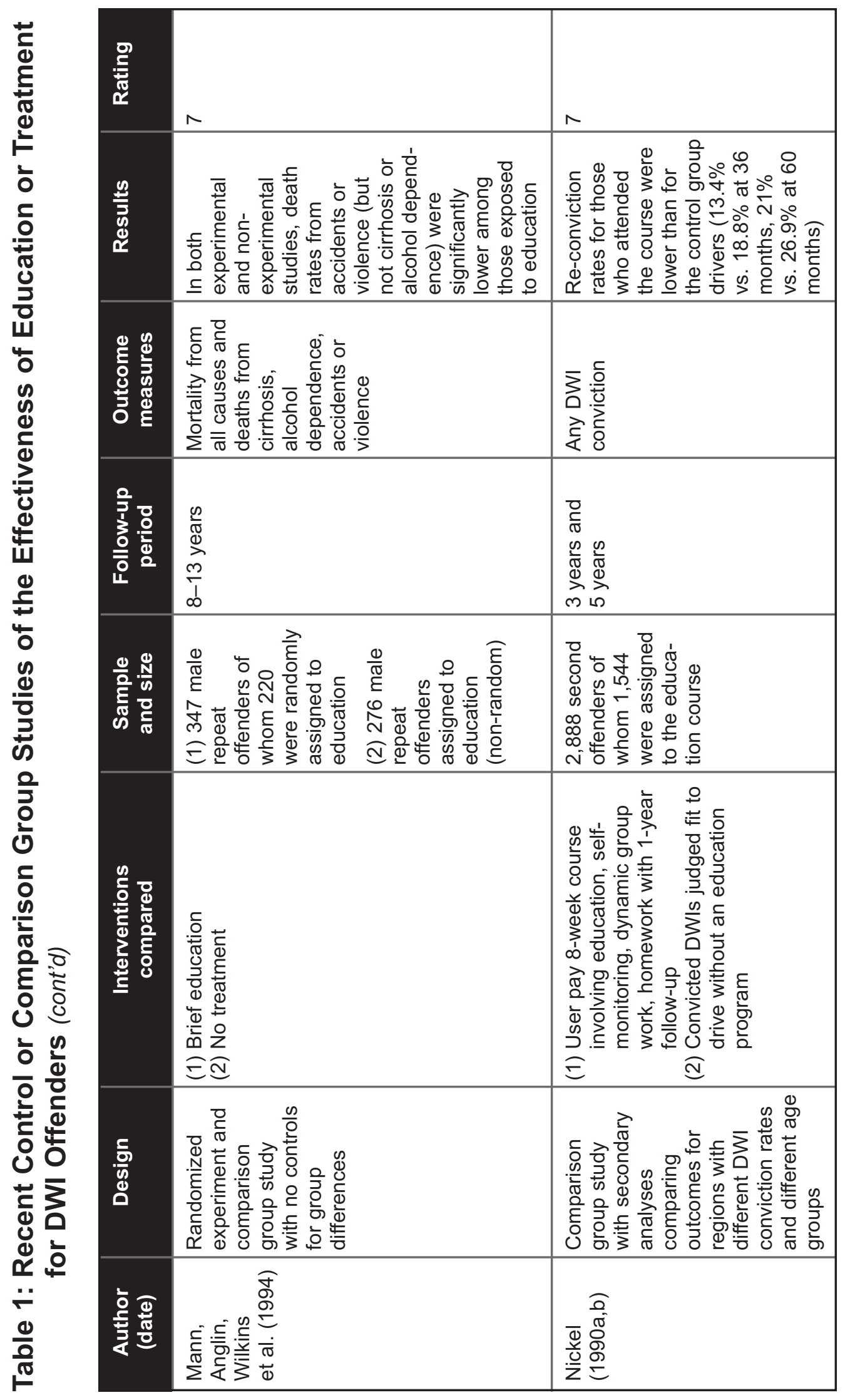

22 | Best Practices - Treatment and Rehabilitation for Driving While Impaired Offenders 


\begin{tabular}{|c|c|c|c|}
\hline 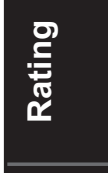 & & 0 & 0 \\
\hline 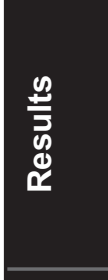 & 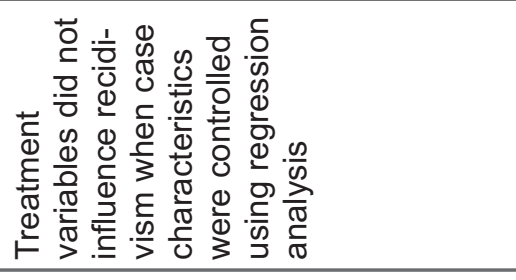 & 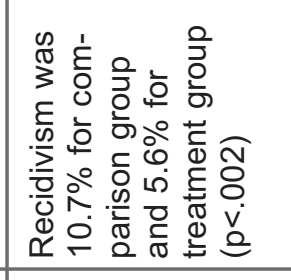 & 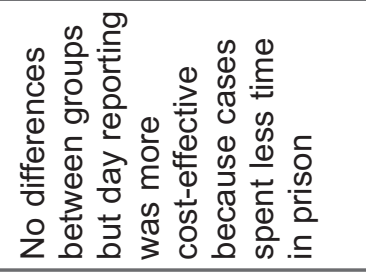 \\
\hline 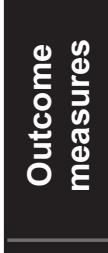 & 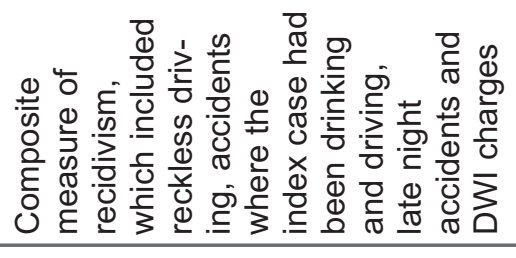 & 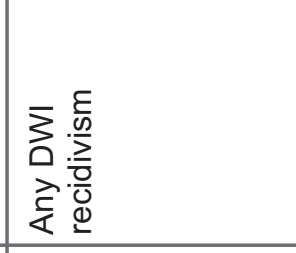 & 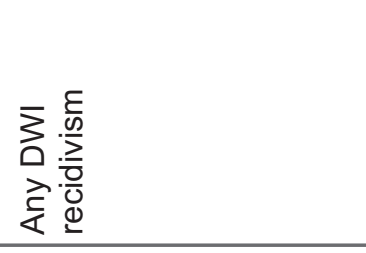 \\
\hline 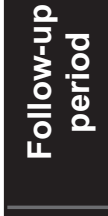 & 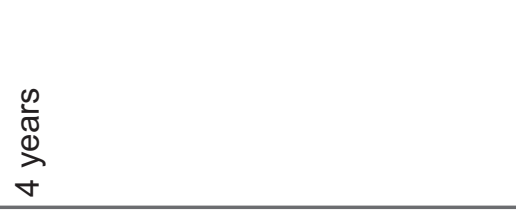 & 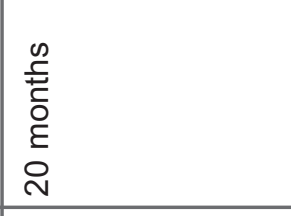 & 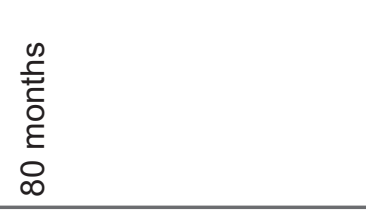 \\
\hline 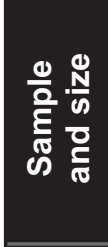 & 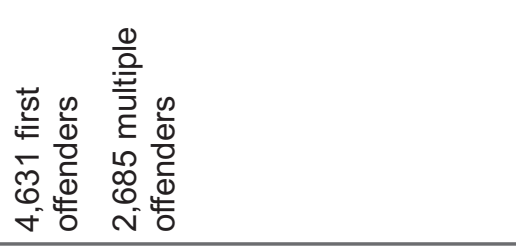 & 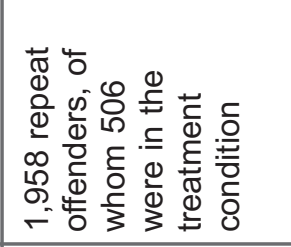 & 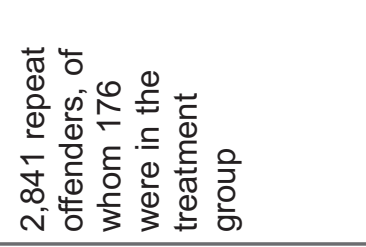 \\
\hline 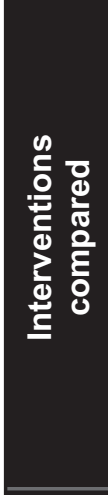 & 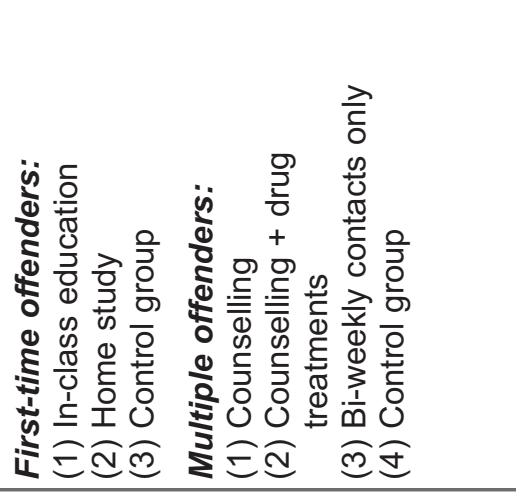 & 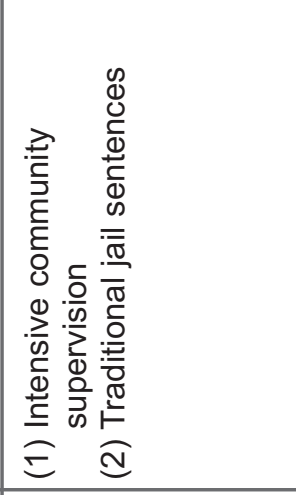 & 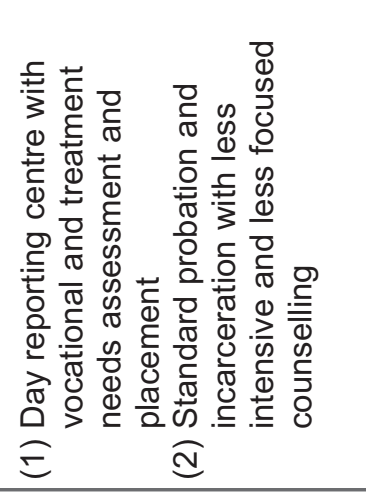 \\
\hline $\begin{array}{l}\frac{5}{5} \\
\bar{\phi} \\
\end{array}$ & 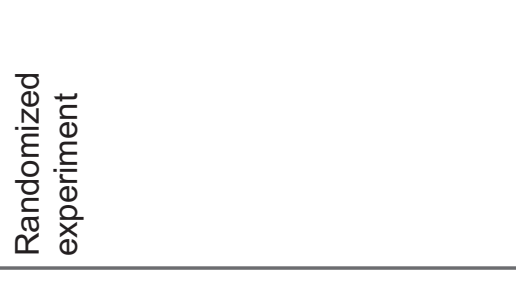 & 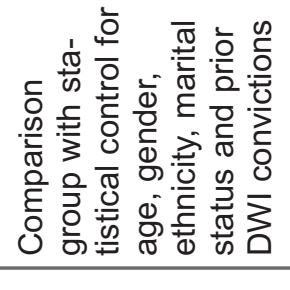 & 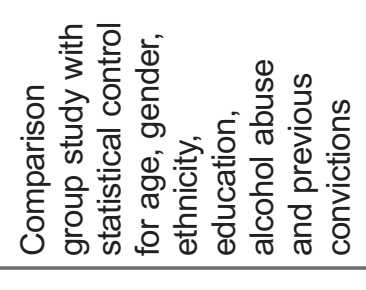 \\
\hline 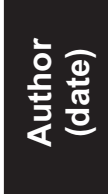 & 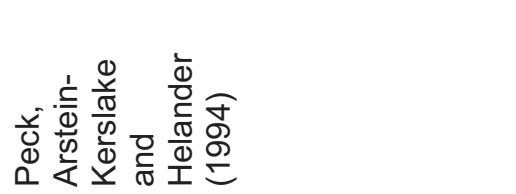 & 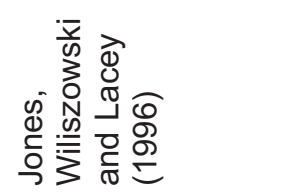 & 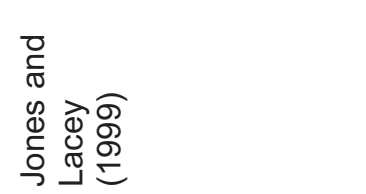 \\
\hline
\end{tabular}




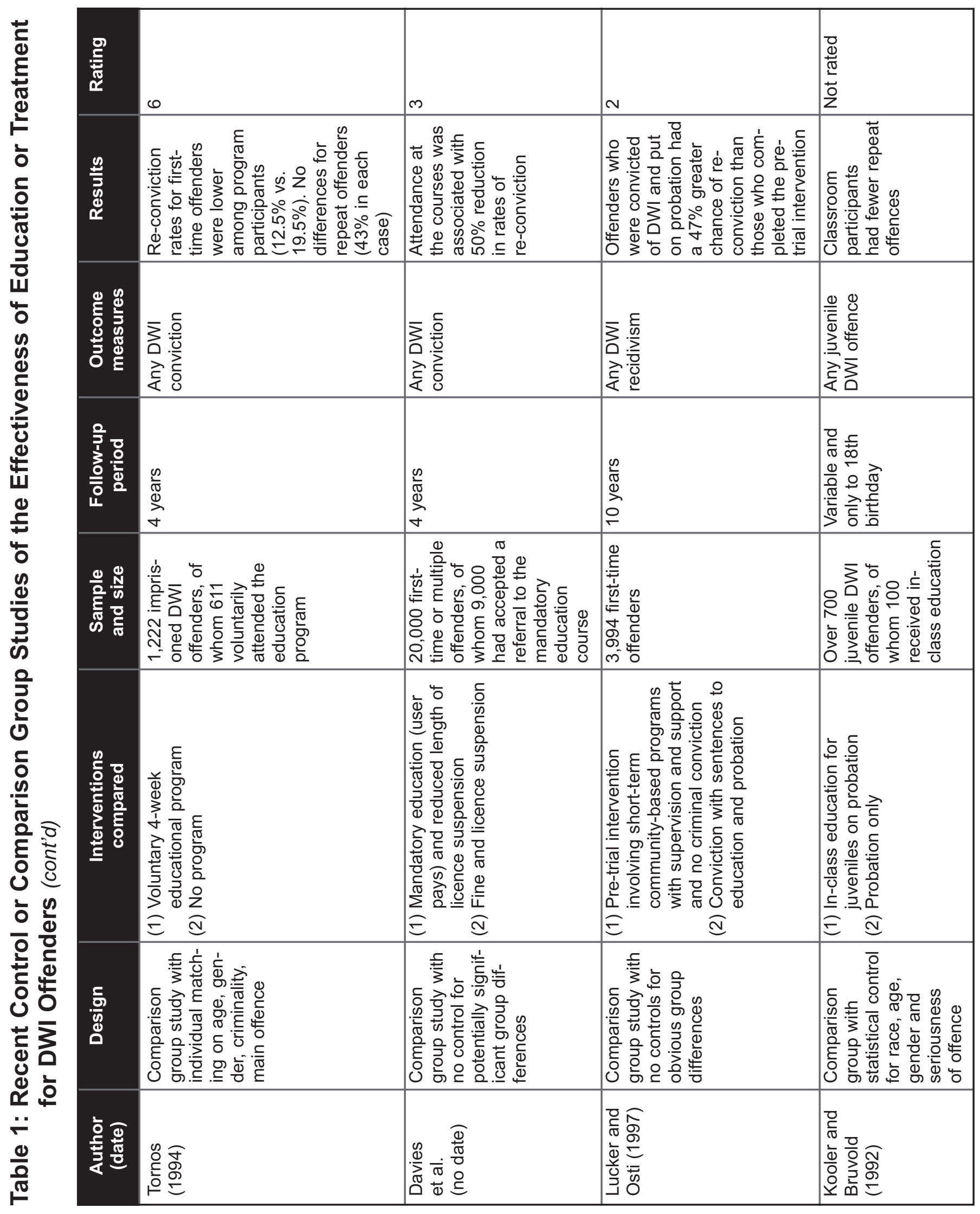

24 | Best Practices - Treatment and Rehabilitation for Driving While Impaired Offenders 
The results indicated that for all offenders, remedial interventions (education and treatment), but not punishment, were associated with a lower relapse rate. However, the analysis did not consider the combined effects of the remedial programs and punishment. Those who had been given a probation order prior to sentence were less likely to re-offend than others and among first-time offenders there were no significant effects for treatment. For all cases, recidivism was associated with being older and having prior DWI convictions.

DeYoung (1997) examined the effectiveness of alcohol treatment, driver's licence actions and jail terms in reducing impaired-driving recidivism. He used a quasi-experimental design to compare re-conviction rates and time to first re-conviction over an 18-month period for convicted first-time, second-time and multiple DWI offenders receiving various dispositions from the courts. Few details of these dispositions, except for those indicated in Table 1, are provided in DeYoung's report. The sample sizes were very large: 88,552 first-time offenders, 27,292 secondtime offenders and 32,787 third-plus offenders.

All analyses controlled for age and gender, class of licence, convictions, total crashes and fatal or injury crashes over the previous three years, and various characteristics of the community of residence (average injury crash rates, moving traffic violations, average time to travel to work, ethnic composition, unemployment rates and income levels).
Results of the analyses showed that for all levels of prior DWI conviction, combining alcohol treatment with either driver's licence restriction or suspension was associated with the lowest DWI re-conviction rates.

Mann et al. (1994) examined mortality rates for convicted second-offence drinking drivers $(\mathrm{N}=347)$ who had been randomly assigned either to a brief educational program or to a no-treatment control condition. The report indicates that the goals, structure and contents of the program resembled those for other North American programs operating at that time. For eight weeks offenders met weekly in groups for two hours. They were presented with information on the biological and psychological effects of alcohol, legal aspects of drinking and driving, the nature of alcohol abuse and alcohol dependence, identification of personal problems with alcohol and additional resources for dealing with these problems.

Over a follow-up period ranging from 8 to 13 years, $14(11 \%)$ of the controls and $17(7.7 \%)$ of the rehabilitation group died from various causes. Although the difference was not statistically significant using conventional criteria $(\mathrm{p}=0.08)$, deaths from accidental and violent causes (but not cirrhosis or alcohol dependence) were significantly lower in the group assigned to education. Additional comparisons involving cases not randomly assigned to the education or control condition generated similar results. The authors speculated that education programs may reduce driving risk behaviours among early-stage or episodic problem drinkers, but 
may be of limited value for reducing the risk of death from cirrhosis or alcohol dependence among those who have patterns of chronic alcohol use problems.

Nickel (1990a,b) reported on an evaluation of a well-established educational user-pay program for first-time DWI offenders in Germany. The program was based on a group-dynamic approach. DWI offenders were assigned to the program if they were judged unfit to drive without it. Participants signed a contract indicating that they would attend all sessions, be punctual, abstain from alcohol on the day of a session and complete all homework assignments.

The program began with a two-week series of activities in which participants were asked to monitor drinking patterns and complete a series of homework assignments. The main course activities involved six weekly small-group sessions in which the participants discussed drinking patterns, identified drinking and driving habits and learned self-observation and self-control as ways to induce behavioural change. During the subsequent 18 months, participants received information letters and were asked to complete further homework assignments. This continued contact was intended to reinforce the lessons and provide support and encouragement to continue the process of behavioural change. After attending six small-group sessions, participants received a certificate that was to be used to reinstate the driver's licence. The group reconvened after 24 months to discuss any difficulties and problems and to check on progress.
Nickel found that re-conviction rates for 1,544 program participants after 36 months were lower than those for 1,344 convicted DWI offenders who were judged fit to drive without attending the program (13.4\% vs.18.8\%). After 60 months, the re-conviction rates were also lower for the program participants (21\% vs. 26.9\%). Although these differences may seem small, they are remarkable because the control groups were assessed as being fit to drive without an education program and would thus be expected to have a lower re-conviction rate.

Nickel found that regional differences in the intensity of law enforcement and drinking habits did not influence differences in re-conviction rates between program participants and others. However, differences were greater for older subjects while the re-conviction rates for those aged 18 to 24 were the same for program participants and others. Among participants, re-conviction rates were also influenced by marital status (higher if not married) and period of licence suspension (higher if period shorter). Among both program participants and others, multiple re-convictions were more common among younger cases, those with a previous hit and run offence, those who had driven without a licence, those who recidivated in a shorter time period, those who reported no impairment with a BAC of $80 \mathrm{mg} \%$, those who were drinking at age 14 , and those who reported having problems with their spouses or friends.

Jones, Wiliszowski and Lacey (1996) compared: (1) pre-trial intensive community supervision and attempts to enhance treatment engagement with (2) traditional jail sanctions. Their report 
also compares in-home confinement and electronic monitoring with traditional jail sanctions (beyond the scope of this report).

The treatment group $(\mathrm{N}=506)$ were repeat offenders who, after arrest, were offered (but not guaranteed) a reduced jail sentence if they participated in the program. The program aimed to reduce impaired driving by addressing drinking habits and drinking problems among those involved. It featured at least bi-weekly contact with probation officers for four to five months. These officers monitored their clients' progress and needs and, where indicated, made referrals to appropriate treatment agencies.

The comparison group $(\mathrm{N}=1,452)$ were repeat offenders who were not offered or who did not accept assignment to intensive probation and treatment. Instead, they went to jail followed by probation. Assignment to the new program was based on multiple considerations, including motivation.

Survival analysis was used to compare recidivism rates over a maximum of 20 months for the two groups. The analysis controlled for age, sex, ethnicity, marital status and number of prior convictions. After adjusting for these variable, the one-year recidivism rate for the experimental group was $5.6 \%$, and $10.7 \%$ for the control group. This difference was highly significant statistically and would occur by chance less than two times in 10,000 if the intervention studied had no effect. There were also cost savings associated with the new program, principally associated with reduced time in jail for those given intensive community supervision.
Jones and Lacey (1999) reported a comparison group study involving DWI offenders assigned to a Day Reporting Centre (DC) or to a standard probation program. Both groups involved offenders who had been charged and convicted of serious DWI offences and had initially been sentenced to at least four months in prison. Both groups received some form of treatment or counselling (not specified) and visits with a probation officer four times a year for four years. However, the treatment for those in the DC group was based to a greater extent on assessment and appropriate placement in programs.

Those in the DC group were also assessed for job skills and educational needs and then placed into specific programs as appropriate. While in the program, the offenders had at least two contacts per week with probation officers and had to seek employment. Participation lasted for one to two months in lieu of a similar period of incarceration and was followed by standard probation. Assignment to the DC program was not random but based on multiple considerations, including motivation.

Post-assignment data on DWI convictions were reported for 176 cases in the DC program and 2,765 given standard probation. Survival analysis was used to compare recidivism over a maximum of 80 months for the two groups. Covariates include age, sex, ethnicity, education, alcohol abuses (yes/no) and variables concerning previous convictions. The results showed that the DC program was no more effective than standard probation in reducing recidivism. However, it was more cost-effective because it reduced time in prison. 
Tornos (1994) reported on an evaluation of an educational program for incarcerated impaired drivers in Sweden. The program was voluntary and generally involved daily lectures for five days each week, over a four-week period. The aim was to educate participants about the risks of drinking by providing information on topics such as the physiological and psychological effects of alcohol, effects on driving and traffic safety and impaired driving legislation. Lectures were given by prison staff, AA members, psychologists, doctors and lawyers.

For first offenders, the recidivism rate within four years was $12.5 \%$ for participants and $19.5 \%$ for a control sample whose members were individually matched on age, gender, criminality, main offences, and months of imprisonment. For similarly matched repeat offenders, the recidivism rates were very similar (about 43\%).

Davies et al. (no date) examined re-conviction rates over three years for more than 20,000 drinking-driving offenders in the United Kingdom, of whom 9,000 (45\%) had attended mandatory education courses. However, offenders did not have to accept a referral to the education course. Those who completed the course could earn a reduced period of licence suspension. There was considerable variation in the proportion of offenders assigned to education in different jurisdictions and this was used as a control for the effects of subject selection bias. The authors interpreted their results as showing that the drinking-driver rehabilitation courses reduced re-conviction rates by slightly more than $50 \%$. Some further analysis suggested offenders aged 30 to 39 may have benefited from the courses more than others and that men may have benefited more than women. However, the differences were small and no analyses that controlled for other offender characteristics were undertaken.

Lucker and Osti (1997) reported on an evaluation of pre-trial intervention (PTI) for DWI offenders, which was available for some DWI offenders at the time of their arrest. This involved 3 to 12 months of supervision and supportive counselling from a probation officer and was an option for offenders who were legal US residents with no criminal records who had not previously received a PTI and whose current offence did not involve violence, drugs or serious property damage. Those choosing the PTI option could avoid the usual criminal court procedures and have all charges dismissed if they completed the program. However, they were also required to attend a 12-hour statecertified DWI course where they were given factual information about the effects of alcohol and encouraged to become aware of their own substance use and driving habits, and to develop plans to reduce future DWI occurrences. Those who did not choose the pre-trial intervention or who were ineligible for it were also required to attend this course.

Survival analysis was used to compare the risk of re-arrest for up to10 years for 3,994 firsttime DWI offenders who either: (1) chose a PTI program, or (2) were convicted of DWI and sentenced to DWI education classes and probation. The results indicated that those convicted of DWI and put on probation had a $47 \%$ greater risk of a re-arrest for DWI than those who completed the PTI program. 
The authors concluded that the PTI reduced recidivism and costs to the publicly financed criminal justice system. This conclusion may not, however, be warranted because no attempts were made to show that those who completed the PTI program had the same base-line characteristics as those who either failed to choose this option or were ineligible to receive it. The selection process suggests that these differences may have been quite significant and likely to lead to different outcomes independent of the influence of the PTI.

Kooler and Bruvold (1992) evaluated an educational intervention for juveniles found guilty of DWI. Over 700 juveniles convicted of DWI formed the study group and, of these, $100 \mathrm{had}$ been referred to an 18-hour educational program by their probation officers. About $60 \%$ of non-referrals were from a time before the education program was available; however, the report does not indicate why some were or were not referred once the program started.

Pre-post measures of those participating in the program indicated increased knowledge, stronger attitudes against driving while impaired and less self-reported alcohol use and risky automobilerelated behaviours. County juvenile records of offences committed prior to age 18 were also examined and class participants were found to have significantly fewer repeat offences compared with non-participants. According to the authors, this could not be explained by race, offence severity, age or gender.

This study does, however, have significant limitations. Forty-two percent of those involved in the study were within six months of their 18th birthday on referral to the education program and thus had only a short time to re-offend.

\section{Discussion}

As with the earlier studies reviewed by WellsParker et al. (1995), these more recent studies vary in methodological rigour. As with earlier studies, most of those that are methodologically weak (Davies et al., undated; Jones, Wiliszowski and Lacey, 1996; Kooler and Bruvold, 1992; Lucker and Osti, 1997; Tornos, 1994) support the remediations evaluated. However, with the exception of the study by Peck, ArnsteinKerslake and Helander, (1994), the methodologically more robust studies also indicate that remediation (but not victim impact panels) can reduce the risk of DWI recidivism, especially in combination with legal sanctions (DeYoung, 1997).

Overall then, the literature supports education and treatment for DWI offenders. Several welldesigned studies with large samples and longterm follow-up intervals have produced positive results and, on balance, the degree of support for DWI remediation is as strong as that for remediations that target other populations with alcohol use problems.

As previously noted, the Wells-Parker et al. (1995) meta-analysis indicated that treatment strategies that combined education, psychotherapy with follow-up and aftercare were most effective for multiple and first offenders. However, some reports provided few details of the kinds of treatments considered. This is also the case for many of the new reports reviewed above. Exceptions are the reports by Nickel (1990a,b). These include fairly detailed descriptions of the program studied and involved a variety of components, including education, self-monitoring, dynamic group work and follow-up. 
No studies of the impact of a remedial program for individuals convicted of driving while impaired by drugs other than alcohol were located. However, studies that evaluate the effects of treatment for drug use problems on driving measures have begun to appear. Mann et al. (1995) examined driver records of 137 males between the ages of 21 and 40 before and after treatment. About one third of the sample had a problem with alcohol use only, one third had a problem with alcohol plus one other substance, and one third had a problem with the use of one or two substances other than alcohol. Overall, significant post-treatment reductions were found in moving violations, DWI convictions and total collisions, and no differences in outcome between drugs were observed, suggesting that treatment for drugs other than alcohol can positively affect driving behaviours.

Macdonald et al. (2002) examined the driving records of patients admitted to substance abuse treatment in 1994 for a primary problem of alcohol $(\mathrm{N}=128)$, cannabis $(\mathrm{N}=80)$ or cocaine $(\mathrm{N}=150)$. A comparison group of 507 licensed drivers matched by age, sex and place of residence was randomly selected for comparison purposes. All three drug groups had significantly higher collision rates in the five years prior to treatment. In the five years after treatment, the collision rates for the alcohol and cocaine group did not differ from controls, while the collision rates of the cannabis group remained elevated. In a subsequent study, Macdonald et al. (2003) conducted telephone interviews with 110 clients treated in 1995 for a problem with alcohol $(\mathrm{N}=44)$, cannabis $(\mathrm{N}=37)$ or cocaine $(\mathrm{N}=29)$, and a randomly selected sample of 104 drivers from the general population, matched by age, sex and place of residence. Prior to treatment, the drug groups reported significantly higher collision rates, while after treatment no differences between the treatment and control groups were observed. As well, treatment subjects reported significant reductions in driving after the use of alcohol, cannabis and cocaine following treatment. Thus, there are indications in the literature that treatment for at least some forms of drug use problems are associated with decreases in DWI by drugs and associated collisions.

Some research on treatments for the general population of people with substance use problems suggests that those with low to moderate alcohol dependence may benefit more from programs where they are allowed to choose abstinence or reduced drinking as a goal than from programs that only have abstinence goals (Institute of Medicine, 1990). However, the impact of goal choice on drinking and driving has not been studied. Such a choice is, of course, often denied to DWI offenders by the courts and many treatment programs also require all clients to have a goal of complete abstinence. It is not known if programs that allow a choice of goals permit such a choice among DWI offenders who are ordered by the court to refrain from the use of alcohol or drugs. 


\subsubsection{Key informant interviews}

Most, but not all, key informants recommended that both first and repeat offenders should have some type of remedial intervention and that this should occur as rapidly as possible following a DWI conviction. Offenders, whether in education or treatment, should be provided with information on the effects of alcohol and other drugs on driving, and the laws on drinking and driving in Canada.

Issues related to drug-impaired drivers were raised by a number of key informants. Issues identified included driving while impaired by psychoactive medication, the need to develop risk levels for drug-impaired drivers, and the need for police to have tools/methods to detect people driving while impaired by drugs other than alcohol. Key informants also endorsed screening/assessment for all substances.

There was no consensus regarding the involvement of family members in educational or treatment interventions. Some felt that successful treatment required family involvement, particularly for youth, while others were concerned that requiring family involvement could be seen as coercive or could possibly pose a risk to family members in situations of domestic violence.

The issue of effective ways to provide ongoing monitoring and support for DWI offenders was raised by a number of key informants, particularly for repeat offenders. Several key informants mentioned the restorative justice model (an approach to criminal justice that gives a balanced focus to the offender, victim and community) and the need to involve a wide range of people and systems in providing monitoring and support.

\subsubsection{Best practices}

Remedial programs for convicted drinking drivers have become increasingly used over the past decades. There is good empirical evidence that they can positively influence knowledge, beliefs, attitudes, alcohol use, recidivism, collisions and the health status of convicted DWI offenders.

\section{Best Practice 1}

Remedial programs should occupy an integral place in a comprehensive impaired driving countermeasure program. Participation in such programs should be a condition of licence reinstatement for all persons convicted of an impaired driving offence.

Less is known about other drugs and driving than about alcohol and driving. However, there are clear indications that the use of certain drugs (including medications) can impair the ability to operate a vehicle safely and increase the risk of fatal crash involvement. There is also preliminary evidence that treatment for drug abuse is associated with post-treatment reduction in motor vehicle collision rates.

\section{Best Practice 2}

Remedial programs should also be an integral part of comprehensive efforts to reduce driving while impaired by drugs other than alcohol. Participation in such programs should be a condition of licence reinstatement for all persons convicted of a drug-related driving offence. 


\subsection{Effectiveness of different types of treatment interventions for different types of impaired drivers}

\subsubsection{Indications from the literature}

Many jurisdictions with remedial programs for DWI offenders have two or more levels of interventions for those judged to have more or less serious substance use problems. Those judged to have less serious problems often receive education, while others may receive both education and some type of therapy designed, for example, to increase motivation for reducing excessive alcohol or drug use, to help offenders to identify and plan for high-risk situations, and to promote lifestyle changes.

Some of the studies noted in the first section considered the relative effectiveness of different types of interventions and outcomes for different types of offenders, particularly first-time or repeat offenders. In general, first-time offenders seem to benefit more from education and treatment than multiple offenders, but it is also possible that other sub-types of offenders may benefit more from particular types of education or treatment.

Manitoba has had a province-wide program for persons convicted of a first or subsequent DWI offence since 1986 (Health Canada, 1997). In 1986, the current Impaired Drivers Program was established. The program is mandatory for first and subsequent impaired driving offenders prior to reinstatement of their driving privileges. Offenders are placed into one of the following four interventions on the basis of an assessment involving the Substance Abuse/Life

\section{KEY POINTS}

- The literature supports the need for all remedial interventions to include, at a minimum, education regarding alcohol and traffic safety, an examination of one's substance use and driving behaviour, and strategies to avoid driving while impaired.

- For offenders at higher risk, additional components with greater emphasis on therapeutic interventions are required.

Circumstances Evaluation (SALCE) (see Table 2) and a structured interview by a trained addictions counsellor:

\section{No intervention}

No intervention occurs when cases are assessed as having no apparent substance use problem requiring further services and are deemed not to be at risk of re-offending. They are judged to be taking responsibility for the offence committed and have viable alternative plans to prevent further offences. They may have already made lifestyle changes prior to accessing the program. No further action is taken to provide education or treatment to this group.

\section{Presumptive problem}

These offenders are judged to be using alcohol or other drugs in a high-risk manner. There are two possible referral options: 


\section{(i) Educational workshop}

This is a one-day workshop that aims to help participants to develop alternative plans to drinking and driving. The workshop provides accurate information on alcohol and drugs, and their effects on driving. It emphasizes the need to keep drinking behaviours separate from driving. The workshop is also designed to be interaction-oriented, with groups of 10 to 12 .

Those referred to the workshop are considered to be at risk of re-offending, due mainly to a combination of not taking responsibility for the offence; not having viable options to prevent further incidents of impaired driving; engaging in high-risk behaviours as identified through their driving abstract or lifestyle (e.g. not considering the potential consequences to their employment when it is dependent on a driver's licence); and/or not being able to gain insights easily into the need to make lifestyle changes.

\section{(ii) High-risk program}

The program spans an average of three to six months, including an average of nine hours of contact with program staff. It is delivered through a series of individual and group sessions, involving a minimum of three individual sessions and a maximum of six group sessions. During the initial phase of involvement, the agreement calls for total abstinence. In the latter half of the program, the participant and counsellor negotiate whether abstinence or moderate drinking will be the behaviour adopted.
Throughout the program, participants are encouraged to discuss any problems they have with abstinence or moderate drinking. If the problems are great, then it may be viewed as indicative of a possible substance dependence, and a referral to a treatment program is considered.

Criteria used to select offenders for this program include some combination of (a) periods of over-using substances, which may also include episodic reduction in consumption or abstinence; (b) inability to link his/her behaviour with subsequent consequences; (c) no obvious signs of substance dependence; (d) previous involvement with the impaired drivers program; (e) demonstrable risks in lifestyle as evidenced by substance use that compromises personal health; (f) lifestyle centred around heavy consumption; (g) family/work concerns related to alcohol/drug use, or (h) the need for a more in-depth program to gain insights into the need to make lifestyle changes.

\section{Specialized abstinence-based residential or non-residential addictions treatment program}

Offenders referred to these programs are currently experiencing the signs and symptoms of a substance dependence. They are referred to a particular program depending on their needs. 


\section{Referral to resources previously found to be helpful}

Those who have a substance dependence and are in recovery with a lifestyle that supports abstinence are required to maintain abstinence and are referred to the resources that they have found helpful in the past. An associated person is contacted periodically over a two-year period to verify self-reported abstinence.

A report prepared for Health Canada (1997) indicates that the Manitoba program is well regarded across the country and appears to have a positive impact on some offenders. However, it has not been evaluated using an experimental or quasi-experimental design due to ethical considerations involved in mandatory programs.

One of the few studies to empirically examine "offender by intervention" interactions in a DWI offender population found interactions involving several demographic characteristics and supportive counselling (Wells-Parker et al., 1988). For this study, DWI offenders were randomly assigned to a variety of interventions, including supportive monthly counselling in a year-long probation context and licence suspension only. The probation-based supportive counselling was found to be especially effective for younger (under 30) minority group offenders (primarily African American). Programs combining traditional short-term DWI interventions with supportive counselling and probation were most effective for this group. The study also suggested that women might be more responsive to all interventions than men, but the numbers were too small to draw firm conclusions.
Another more recent study (Wells-Parker and Williams, 2002) considered possible interactions between different types of treatment and selected characteristics (age, gender, minority group membership and depression). In this study, first-time DWI offenders ( $\mathrm{N}=4,074)$ were randomly assigned to a standard firstoffender program or an enhanced standard program that included two short individual sessions and a brief follow-up session. Over a 28 to 55 month follow-up interval, offenders classified as suffering from depression who were assigned to the enhanced program were $35 \%$ less likely to recidivate than those assigned to the standard program. However, no significant interaction effects were found between program type and age, minority status or gender. The authors concluded that a combination of a standard first-offender program with brief individual counselling can be effective for DWI offenders who report depressed moods and who are at high risk for recidivism.

Only one other study (Ball et al., 2000) has considered the benefits of matching different types of DWI offenders to different treatments. However, this study did not use post-treatment DWI offences as an outcome measure.

Despite the limited evidence in favour of matching, some researchers believe that there is still much to be learned and many attempts have been made to develop typologies of DWI offenders to guide research and to inform clinical practice. Attempts to identify sub-types of DWI offenders using cluster analysis or other statistical methods have found a substantial minority ( $40 \%$ or more) with few risk factors for recidivism, and others with various types of risks, 
including alcohol use problems, bad driving habits, psychiatric problems, social instability, impulsiveness, sensation seeking, hostility, depression and anti-social attitudes (Donovan and Marlatt, 1992; Donovan, Umlauf and Slazberg, 1988; Macdonald and Mann, 1996; Wieczorek and Miller, 1992; and Wilson, 1991).

McMillen et al. (1992) found first-time and multiple DWI offenders differed significantly with respect to personality traits, drinking behaviour and problems, and driving behaviours. More specifically, multiple offenders had higher scores on measures of hostility, sensation seeking, psychopathic deviance, mania and depression than first offenders. Multiple offenders were also significantly lower in emotional adjustment and assertiveness and had more non-traffic arrests, accidents and traffic tickets than first offenders. They also consumed significantly more alcohol, evidenced more alcohol use problems and had higher BACs at the time of arrest than first offenders.

Wells-Parker, Cosby and Landrum (1986) also found that DWI offenders could be grouped on the basis of their previous traffic and criminal records. Five groups were identified using cluster analysis. The largest group encompassed offenders with few previous offences. Other groups comprised offenders who mainly had traffic offences, licence and equipment offences, public drunkenness offences or a mixture of offences.

One recent study (Chang, Lapham and Wanberg, 2001) used scores from the Alcohol Use Inventory (AUI) (Horn, Wanberg and Foster, 1987) to develop a typology of first-time DWI offenders and to determine if some types were more likely to re-offend than others. Six types were identified using cluster analysis. The largest encompassed $50 \%$ of all cases and members had low scores on all AUI scales. Other types were variously distinguished with respect to scores on measures of alcohol preoccupation, anxiety and the enhancing or disruptive effects of drinking. Predictors of recidivism included male gender, young age, less education, high arrest $\mathrm{BAC}$ and presenting high scores on disruptive and/or enhancing effects of alcohol scales.

Another multi-dimensional classification scheme with implications for treatment planning has been proposed by Cavaiola and Wuth (2002). This was used at one of the largest DWI programs in the United States (in Cook County, Illinois). This scheme is based on the results of self-administered questionnaires, face-to-face interviews with offenders and significant others, and objective data such as previous convictions. Offenders are assigned to one of six "level of risk" categories:

- Minimal: No prior convictions or courtordered supervision for DUI; no prior statutory summary suspension; no prior reckless driving invocations reduced from DUI; a BAC of less than $.15 \mathrm{~g} / \mathrm{dl}$ at the time of the arrest for DUI; and no symptoms of substance abuse or dependence.

- Moderate: No prior conviction or courtordered supervision for DUI; no prior statutory summary suspension; no prior reckless driving conviction reduced from DUI; a BAC of .15 to .19 or a refusal of chemical testing at the time of the current DUI arrest; and no other symptoms of substance abuse or dependence. 
- Significant: One prior conviction or courtordered supervision for DUI, one prior statutory summary suspension, or one prior reckless driving conviction reduced from DUI; and $/$ or a BAC of $.20 \mathrm{~g} / \mathrm{dl}$ or higher at the time of the most current arrest for DUI and/or other symptoms of substance abuse.

- High: Symptoms of substance dependence, no prior arrest.

- High +: Two prior convictions or courtordered supervisions for DUI, two prior statutory summary suspensions, or two prior reckless driving convictions reduced from DUI within a ten-year period from the date of the most current (third) arrest.

- High ++: Symptoms of substance dependence and two prior convictions or courtordered supervisions for DUI, or two prior statutory summary suspensions, or two prior reckless driving convictions reduced from DUI within a ten-year period from the date of the most current (third) arrest. (Cavaiola and Wuth, 2002, pgs. $165-166$ )

To return to the issue of matching, it is of note that the broader literature on substance abuse treatment includes some studies indicating the benefits of matching clients to treatment, but it cannot be assumed that the results can be generalized to DWI populations. There is, however, a consensus among service providers that a variety of flexible and individualized services are needed to address the variety of problems presented by clients of specialized substance abuse services. As stated in a Health Canada report:

Some clients need services for mental health problems, others require help with employment and other social problems, and some will need temporary or longer-term shelter. Attention to these problems is essential if those involved are to achieve and maintain improvements in substance use behaviours.

(Health Canada, 1999, p. 24)

These points have been further elaborated with respect to treatment for alcohol-impaired drivers by a committee of experts convened by the US Century Council (1997), and there are no good reasons to believe that the issues differ for drivers impaired by other drugs. The Century Council recommends that treatment for DWI offenders should be:

- based on a personalized assessment process that is needed to evaluate an individual's use of, or dependence on, alcohol;

- individualized to meet the needs of each offender;

- based on a combination of strategies, such as education with therapy, plus follow-up; and

- provided over a sufficient period of time for meaningful behaviour changes to occur, and be monitored. 
The Century Council's expert committee also indicated that treatment should not be a substitute for other sanctions, especially licence suspensions. It noted that treatment has its largest impact on recidivism when it is combined with sanctions such as licence suspensions and interlock requirements.

Mann et al. (1997) reviewed the DWI treatment literature, the broader literature on substance abuse treatment and the literature on the treatment of offenders to identify the most important elements for comprehensive remedial programs for DWI offenders. They proposed the following components for programs intending to address a diversity of needs:

- alcohol and traffic safety education;

- motivational enhancement to cut down excessive drinking;

- consciousness raising concerning the individual's quantity, frequency and pattern of drinking;

- identification of high-risk situations, and planning;

- rehearsal of alternative coping skills;

- promotion of lifestyle changes;

- social support for reduced drinking or abstinence;

- information on further treatment options; and

- the opportunity to choose abstinence or moderate drinking as a program goal.
Mann et al. (1997) also noted that the literature shows the importance of dealing with clients in a non-judgmental manner.

The literature supports the need for all remedial interventions (including those for offenders at no or low risk of recidivism) to include, at a minimum, education regarding alcohol and traffic safety, and an opportunity to examine their substance use and driving behaviour and to develop strategies to avoid driving while impaired in the future. These objectives are best met through participatory instructional strategies, based on sound adult education practice. For offenders at higher risk, additional components with greater emphasis on therapeutic interventions are required (Century Council, 1997; Mann et al., 1997).

\subsubsection{Key informant interviews}

Key informants supported the need for multiple levels of intervention to ensure that offenders were not over-treated or under-treated, and for interventions that were client-centred and tailored to each client's strengths and problem areas as identified in the screening/assessment process. "One size does not fit all" was expressed by a number of key informants. Based on current practice across the country, these different levels of intervention would address the needs of those who require education regarding the effects of alcohol (BAC) and DWI legislation; are considered higher risk because of their attitudes and behaviours regarding drinking and driving and/or are at an early stage of a substance use problem; and have a serious substance use problem. A group format was considered the most cost-effective 
intervention modality for DWI offenders. Though it was generally felt that educational interventions were appropriate for many first offenders, key informants also cautioned that assignment should be in the context of the results from screening/assessment.

Several key informants recommended that offenders, particularly repeat offenders, be regularly monitored for periods that would be determined by relapse pattern and rating of risk. Key informants were particularly concerned about offenders who they felt continued to pose a risk for drinking and driving and that they should continue to be monitored following licence reinstatement.

\subsubsection{Best practices}

It is widely assumed that two or three levels of intervention are needed: (1) education for those at a lower risk for relapse, (2) outpatient treatment and (3) more intensive treatment for those at higher risk due to the severity of their substance use problem. This assumption is reflected in the practices of many jurisdictions. Although the empirical support for such arrangements is limited, clinical experience supports the value of having two or three levels of intervention.

\section{Best Practice 3}

Comprehensive remedial programs for convicted impaired drivers should incorporate at least two levels of intervention for individuals with differing levels of substance use and related problems.
Available research identifies effective components that can be incorporated into all programs, regardless of length. Programs that rely solely on a didactic approach, or on an attempt to confront clients with the consequences of their actions, appear to be less effective than programs that incorporate both educational and therapeutic activities, regardless of the length or intensity of the program.

\section{Best Practice 4}

All programs for convicted DWI offenders should incorporate both educational and therapeutic activities, regardless of program length.

Follow-up is widely considered to be a central aspect of effective substance use treatment and programs for convicted impaired drivers. With convicted impaired drivers, follow-up can serve several important purposes: it can be as an additional therapeutic contact; it extends the period during which clients are under therapeutic supervision; it aids in the consolidation of the positive behavioural and attitudinal changes made in remedial programs; and it is also a check on the success of the client in maintaining those gains.

\section{Best Practice 5}

Mandatory clinical follow-up after licence reinstatement should be required for all DWI offenders sent to remedial programs. 


\subsection{Identifying impaired drivers who may benefit from particular levels of substance abuse education or treatment}

\subsubsection{Indications from the literature}

As evidenced by the previous section, the population of impaired drivers includes people who differ with respect to many factors that might indicate their need for substance abuse education, treatment or rehabilitation (e.g. frequency of drinking and drug use, severity of substance use problem, impaired driving charges, criminality, personality, motivation to change and psychopathology). They also differ with respect to age, gender, social circumstances and other factors that could influence the outcomes of remedial interventions (Applegate, Langworth and Latessa, 1997; C'de Baca, Miller and Lapham, 2001; Health Canada, 1999; Van Whitloc and Lubin, 1998; WellsParker et al., 2000). There is, however, no simple or consistently reliable method for identifying those most in need of any particular type or level of education or treatment.

A major challenge in the identification of DWI offenders who may benefit from a particular type of remedial program is their tendency to deny or otherwise misrepresent their drinking and drug use behaviours and problems (Lapham et al., 2001). For this reason, some screening and assessment instruments and procedures use objective and/or "disguised" indicators of substance use problems. The most commonly used objective indicators include

\section{KEY POINTS}

- There is a need for different levels of interventions for different DWI offenders as research indicates that they differ in the extent of their substance use and other ways that can influence DWI recidivism.

- There is no simple or reliable method for identifying those most in need of any particular type or level of education or treatment.

- A clearly delineated screening/assessment process is important to support the decisions around matching.

- Several screening instruments, validated using DWI populations and programs, have been identified, and their use is consistent with best practice.

DWI arrest history and BAC level at the time of arrest. However, in neither case do these provide reliable indications of problem severity. Many first-time offenders have significant substance use problems, and BAC at the time of arrest is a poor indicator of alcohol use problems as indicated by other measures (Wieczorek, Miller and Nochajski, 1992). However, BAC level at the time of arrest has been shown to be highly correlated with recidivism (Gjerde and Morland, 1988). Some experts therefore recommend that both arrest history and BAC level at the time of arrest be considered in the context of comprehensive screening and assessment programs. 
Screening and assessment ${ }^{4}$ instruments that feature at least some disguised or indirect indicators of substance use and related problems are the Mortimer-Filkins questionnaire (Mortimer, Filkins and Lower, 1971), the MacAndrew Alcoholism Scale (Revised) (MacAndrew, 1965), the Research Institute on Addictions Self-Inventory (RIASI) (Nochajski and Miller, 1995; Nochajski et al., 1993), and the Substance Abuse Subtle Screening Inventory-ll (SASSI) (Miller, 1994). Brief descriptions are given in Table 2.

Table 2 also includes selected information on commonly used screening questionnaires and inventories that use only "non-disguised" items concerning alcohol or drug use. Thus, the intent of the items is obvious to the respondent and the responses can be influenced by a strong desire to minimize the extent of the problem. In all cases, the choice of cut-off scores influences the percentage of cases correctly identified (true positives) and percentage of cases wrongly identified as having substance use problems (false positives).

Structured interviews can also be used to identify DWI offenders with substance use problems. The gold standard is the Structured Clinical Interview (SCID) for the Diagnostic and Statistical Manual III-R (DSM-III-R) (Spitzer et al., 1990). This requires an experienced interviewer who is required to make clinical judgments regarding the meaning and interpretation of client responses. Each section of the SCID corresponds with one of the major diagnostic categories of the DSM-III-R and, when used to screen cases for alcohol or drug use problems, only those sections that concern substance abuse or dependence are used. The disadvantages of the SCID are that it is time consuming and requires skilled interviewers.

An alternative to the SCID is the Diagnostic Interview Schedule or DIS (Robins et al., 1982). This is simpler to administer and requires very little decision making by the interviewer. The results indicate if the client qualifies for a diagnosis of alcohol or drug abuse or dependence. The DIS has mainly been used in research, but it can also be used clinically. A disadvantage is that, as with other direct screening and assessment instruments, offenders may intentionally minimize the severity of their problem. The same limitation pertains to other structured interviews such as the Addiction Severity Index or ASI (McLellan et al., 1992), the Comprehensive Drinker Profile or CDP (Marlatt and Miller, 1984) and the Timeline Follow Back (Sobell and Sobell, 1992).

Although quite widely used, the SASSI has not been validated with DWI samples, nor has it been shown to be superior to other instruments for detecting people with alcohol or drug use problems in other settings. Gray (2001) found that reliability was generally good for the direct scales but poor for the indirect scales. Neither the Driver Risk Inventory nor the SALCE has been widely validated (Chang, Gregory and Lapham, 2002).

\footnotetext{
${ }^{4}$ Screening generally refers to a relatively brief process designed to identify probable cases (in this instance, cases with substance use problems) and assessment to a more detailed and extended process designed to confirm the results of screening and to generate more detailed information for treatment planning.
} 


\section{Table 2: Selected Characteristics of Commonly Used Questionnaires and Inventories for Identifying or Assessing DWI Offenders with Alcohol or Drug Use Problems 5}

\begin{tabular}{|c|c|}
\hline Instrument & Description \\
\hline $\begin{array}{l}\text { Mortimer-Filkins Test (Mortimer, Filkins } \\
\text { and Lower, 1971) }\end{array}$ & $\begin{array}{l}58 \text { yes/no and short answer items plus structured interview. Items concern } \\
\text { drinking patterns, problems and attitudes, personal/social problems and } \\
\text { lifestyle issues. }\end{array}$ \\
\hline $\begin{array}{l}\text { MacAndrew Alcoholism Scale - } \\
\text { Revised (MAC-R) (MacAndrew, 1965) }\end{array}$ & $\begin{array}{l}49 \text { true/false items derived from the Minnesota Multiphasic Personality } \\
\text { Inventory (MMPI), a widely used clinical assessment instrument; has no } \\
\text { questions about drinking or drug use. }\end{array}$ \\
\hline $\begin{array}{l}\text { Substance Abuse Subtle Screening } \\
\text { Inventory-II (SASSI) (Miller, 1994) }\end{array}$ & $\begin{array}{l}62 \text { true/false items with low face validity for chemical abuse, and } 26 \\
\text { questions that help clients identify negative consequences of their use } \\
\text { of alcohol and other drugs. }\end{array}$ \\
\hline $\begin{array}{l}\text { Research Institute on Addictions } \\
\text { Self-Inventory (RIASI) (Nochajski and } \\
\text { Miller, 1995) }\end{array}$ & $\begin{array}{l}52 \text { yes/no items directly or indirectly related to, or indicative of, drinking } \\
\text { problems. }\end{array}$ \\
\hline $\begin{array}{l}\text { Michigan Alcoholism Screening Test } \\
\text { (MAST) (Selzer, 1971) }\end{array}$ & $\begin{array}{l}25 \text { weighted yes/no items concerning drinking habits, alcohol dependence } \\
\text { symptoms and drinking-related problems. }\end{array}$ \\
\hline $\begin{array}{l}\text { Driver Risk Inventory-II (DRI) } \\
\text { (Lindeman and Scrimgemour, 1999) }\end{array}$ & $\begin{array}{l}140 \text { items directly or indirectly related to, or indicative of, drinking } \\
\text { problems. }\end{array}$ \\
\hline $\begin{array}{l}\text { Substance Abuse Life/Circumstances } \\
\text { Evaluation (SALCE) (ADE Inc., 1986) }\end{array}$ & $\begin{array}{l}85 \text { true/false or Likert items designed to identify behavioural, attitudinal } \\
\text { and clinical indicators of an individual's need to alter alcohol or drug use. }\end{array}$ \\
\hline $\begin{array}{l}\text { Drug Use Screening Inventory (DUSI) } \\
\text { (Tarter and Hegedus, 1991) }\end{array}$ & $\begin{array}{l}149 \text { yes/no items concerning substance use, behaviour patterns, health } \\
\text { status, psychiatric disorders, social competence, family systems, school } \\
\text { performance, work, peer relationships and leisure activity. }\end{array}$ \\
\hline $\begin{array}{l}\text { Drug Abuse Screening Test (DAST) } \\
\text { (Skinner, 1982) }\end{array}$ & $\begin{array}{l}28 \text { yes/no items concerning drug taking, drug dependence symptoms and } \\
\text { drug-related problems - similar to items on the MAST. }\end{array}$ \\
\hline $\begin{array}{l}\text { Alcohol Use Inventory (AUI) (Horn, } \\
\text { Wanberg and Foster, 1987) }\end{array}$ & $\begin{array}{l}228 \text { items concerning benefits of alcohol use, styles of use, negative } \\
\text { consequences of use, concerns about use and acknowledgement that } \\
\text { use causes problems. }\end{array}$ \\
\hline $\begin{array}{l}\text { Alcohol Use Disorders Identification } \\
\text { Test (AUDIT) (Bohn, Babor \& Kranzler } \\
\text { (1995) }\end{array}$ & $\begin{array}{l}10 \text { items concerning amount and frequency of drinking, alcohol } \\
\text { dependence, and problems caused by alcohol. }\end{array}$ \\
\hline
\end{tabular}

\footnotetext{
${ }^{5}$ A number of other instruments with limited research support are used in some US states (Chang, Gregory and Lapham, 2002)
} 
The RIASI has been shown to be superior to the MAST and the Mortimer-Filkins for identifying cases that qualify for DSM-II-R diagnoses of alcohol abuse or dependence (Nochajski, Miller and Parks, 1994). In one study, the RIASI identified $69 \%$ of cases known to have had a lifetime diagnosis of alcohol abuse or dependence, while the MAST identified only $49 \%$ of these cases. The RIASI also identified $79 \%$ of cases with drug-related problems and $80 \%$ of cases that reported driving after using drugs. The corresponding percentages for the MAST were both $38 \%$. These findings have led to the use of the RIASI in place of the MAST and the Mortimer-Filkins instruments in some DWI programs in the United States. However, a recent review of commonly used assessment instruments found that the evidence for predictive validity was strongest for the MacAndrew Alcoholism Scale and the Alcohol Use Inventory (Chang, Gregory and Lapham, 2002). These instruments have been shown to detect about $70 \%$ of DWI recidivists.

There are, however, no clear indications of the superiority of any one screening instrument or set of instruments and procedures, and experts agree that the selection of specific instruments and procedures should be guided by the needs and resources in particular jurisdictions (Beirness, Mayhew and Simpson, 1997).

Further information on screening instruments and various issues in the screening of impaired drivers can be found in two recent publications: Cavaiola and Wuth, 2002, pp. 75-111; and Chang, Gregory and Lapham, 2002.

All of these instruments and procedures can, of course, be used to identify people with substance use problems in other clinical or criminal justice populations or in the general population. This includes drivers charged with traffic offences that are not specifically related to alcohol or drugs. No studies providing advice for substance abuse screening of these drivers were identified in this review. It is of note that Donovan et al. (1985) found that men with multiple non-alcohol-related traffic convictions or accidents had higher levels of drinking than those in the general population of drivers, but not as high as repeat DWI offenders. However, they were similar to repeat DWI offenders on measures of personality, depression and hostility. These results suggest the need for more research concerning substance abuse in the general population of repeat traffic offenders.

\subsubsection{Key informant interviews}

There was agreement among key informants that anyone convicted of a DWI offence, whether a first offence or a repeat offence, should be screened and assessed in order to assign the offender to an appropriate level of intervention. Though not all jurisdictions currently assess first offenders, there was recognition that many first offenders have driven after drinking on many previous occasions, and doing a comprehensive work-up provides an opportunity for earlier intervention.

Most (but not all) key informants also agreed that all offenders should receive some type of intervention, regardless of the results of the screening/assessment, though one jurisdiction provides for a "no further action" option.

There was no agreement among key informants as to whether screening or assessment should occur only after a conviction or after an 
administrative suspension or charge. Some felt that waiting until a conviction would unduly delay the start of education or treatment, while others felt that proceeding with assessment prior to conviction might infringe on civil liberties.

Most key informants felt that screening/assessment procedures should also be applied to drivers of vehicles other than cars, particularly snowmobiles, since alcohol is frequently a factor in snowmobile deaths. Impaired drivers of these other vehicles could be charged under the Criminal Code, but Motor Vehicles Departments would not necessarily be notified.

Several concerns were raised about individuals driving while impaired by psychoactive medication (prescribed or over-the-counter), particularly since people may not recognize the impairing effects of medication. In this context, several key informants commented on the need for tools/ methods to help police in detecting people driving while impaired by substances other than alcohol.

Several key informants noted the importance of having information on arrest BAC, driver history (lifetime) and previous history of education/ treatment as part of the assessment information. It should be noted that for youth, information on arrest $\mathrm{BAC}$ and driver history is not available because of provisions under the Youth Criminal Justice Act. The need for BAC information was not, however, supported by all key informants. One noted that a high BAC may or may not indicate a general pattern of heavy consumption.

In addition to the instruments identified in Table 2, one or more key informants mentioned the CAGE (King, 1986), Alcohol Risk
Assessment and Intervention (ARAI) Guidelines (by the College of Family Physicians of Canada, 1994), the 20 questions of Alcoholics Anonymous (Alcoholics Anonymous n.d.), and the Personal Experience Screening Questionnaire (PESQ) for youth (Winters, 1991). One key informant emphasized the need to use standardized instruments administered by a qualified professional so that results could be defended in a court of law.

A number of key informants raised the issue of the validity of self-report information and concerns that DWI clients "fake good" or minimize the extent of problem substance use. In this context, several key informants noted the importance of using psychometric instruments that include some type of "lie scale"; several mentioned other sources of information, such as information from family, friends or employer. One key informant identified the need for a traffic safety risk assessment, based on such information as history of traffic violations and crashes. This key informant was particularly concerned about the validity of self-report information. Generally, it was felt, and reported as being the practice, that screening/assessment should be done by substance abuse counsellors.

There were mixed responses to the issue of gathering collateral information from family members or others such as friends, physicians and employers, as part of the assessment process. In terms of family members, some key informants indicated that their involvement was critical, particularly for youth, or where there was contradictory information; others raised some concerns about putting family members at risk in situations of domestic violence, the ethical problem in requiring family member 
involvement, and what information provided by the family could be appropriately shared with the client in the assessment feedback process.

There was no consensus regarding the assessment of client readiness to change and use of motivational interviewing approaches with DWI offenders. Some key informants indicated that offender stage of readiness for change was critical in terms of matching the offender to the appropriate type and level of intervention and engaging them in the intervention process, while others indicated that either they had no experience applying this model to a DWI population and/or that it was not appropriate, given that offenders were mandated to treatment thereby limiting the options available to the counsellor.

Most key informants indicated that the majority of offenders were male. Other population groups for which some special provisions need to be made were noted as follows:

1. Women: Ideally, there should be genderspecific screening/assessment (if done as a group process) and intervention, but in most (but not all) jurisdictions this is not practical because of low numbers. In some jurisdictions, particularly large urban areas, women can be referred to gender-specific treatment programs.

2. Aboriginals: For this group, there are issues of language, cultural appropriateness of screening/assessment tools, and process and intervention (in one jurisdiction, they do their own DWI programming).
3. Rural residents: These residents may experience difficulty accessing DWI programs because of distance and lack of public transportation, thus sanctions may be more severe for them; one key informant mentioned rural women in particular because of such barriers as child care and having only one family car.

4. Youth: Some key informants indicated there should, ideally, be specialized programming, while others felt that youth could be part of an adult intervention. Several key informants mentioned the importance of graduated licences and having lower thresholds to trigger sanctions.

5. Older adults: Key informants identified the following issues: stigma; being reluctant to attend an intervention program; and difficulty understanding some of the instruments.

6. Deaf clients and those with low literacy skills: These offenders were also mentioned as needing specialized approaches.

\subsubsection{Best practices}

In principle, it may be possible to identify individuals for whom a remedial program would serve no benefit. Previous practices in many Canadian jurisdictions, where courts assigned some people but not others to remedial programs, were based on this assumption. This practice is still followed in some jurisdictions in the United States and elsewhere. However, there is no support in the research literature for this practice. No methods are currently available that can reliably identify those individuals who will and those who will not benefit from 
remedial programs. In the face of compelling evidence that these programs do have benefits to participants in the aggregate, the best practice is (as identified in best practice statements 1 and 2) to require that all DWI offenders attend some type of remedial program.

The fact that research indicates that DWI offenders differ in the extent of their substance use problems and other ways that can influence the risk of DWI recidivism suggests the need for different levels or types of interventions for different individuals. Although the best ways to match offenders with level or types of treatment have not been determined, in general more intensive interventions may be appropriate for those with more serious problems, and a clearly delineated screening/assessment process is important to support these decisions.

\section{Best Practice 6}

All convicted DWI offenders should complete a screening/assessment process to inform decisions about the most appropriate level or type of intervention.

Several screening instruments that have been validated using DWI populations and programs have been identified, and the use of these instruments by those familiar with their strengths and limitations should be considered consistent with best practice.

\section{Best Practice 7}

Instruments that have been shown to be of value in assessing alcohol and drug use problems and recidivism risk should form part of the screening procedure. The performance of these instruments should be monitored on an ongoing basis.

\subsection{Effectiveness of programs that combine treatment and rehabilitation with licence suspension or other methods for limiting driving opportunities}

\subsubsection{Indications from the literature}

When rehabilitation programs were first being introduced, one strategy that was frequently used to encourage offenders to attend a remedial program was for courts or licensing authorities to offer to reduce or waive the period of licence suspension, which typically is a consequence of a conviction for impaired driving (Mann et al., 1983). However, this substitution strategy proved to be a serious mistake, at least from a traffic safety perspective. Several evaluations comparing offenders sent to rehabilitative

\section{KEY POINTS}

- Greater reductions in impaired driving recidivism and collisions are obtained with a combination of remedial programming and licensing actions such as suspensions and interlock requirements.

programs (who had a licence returned) to control groups not sent to such a program (who were subject to a licence suspension) revealed that those sent to rehabilitation usually had as many or more collisions and convictions at follow-up (e.g. Preusser, Ulmer and Adams, 
1978). This occurred because licence suspensions have important traffic safety benefits (Mann et al., 1991) that are forgone when they are substituted for another measure like rehabilitation.

A subset of the studies included in the WellsParker et al. (1995) analysis involved cases with varying levels or types of education or treatment and/or licensing penalties. It was thus possible to explore the relative influence of education/treatment and legal sanctions or combinations of both. The results indicated that the greatest positive impact on alcoholrelated traffic events and more general traffic safety occurs when offenders receive both education or treatment and licence suspensions.

This conclusion is reinforced by the previously noted study by DeYoung (1997). Also, as previously noted, this was the conclusion reached by the panel of experts convened by the Century Council (1997). Other experts have reached similar conclusions (e.g. National Commission Against Drunk Driving, 2002; Nichols, 1990; Voas and Fisher, 2001;).

\subsubsection{Key informant interviews}

Key informants supported the need for legal sanctions to be combined with educational or treatment interventions. Several emphasized the importance of a balance between education/ treatment and legal sanctions, and raised concerns that making legal sanctions too severe can reduce offenders' motivation to change and encourage driving without a licence. Some key informants raised the importance of offenders taking responsibility for their offence, and the role of the administrative model (see below) in putting the onus on the offender to follow through on requirements for licence reinstatement.

In addition, several key informants indicated that the current system can be confusing for clients because highway traffic acts in different provincial/territorial jurisdictions can increase penalties beyond those imposed under the Criminal Code. Almost all key informants emphasized the need for standardization across provinces/territories in terms of legal sanctions and education/treatment interventions.

\subsubsection{Best practices}

The evidence indicates that greater reductions in impaired driving recidivism and collisions are obtained with a combination of remedial programming and licensing actions such as suspensions and interlock requirements. Previous efforts to use reductions in licensing actions as an incentive to enter remedial programs have found that this policy discards any traffic safety benefits that accrue as a result of remedial programs.

\section{Best Practice 8}

Remedial programs should supplement, not replace, licensing actions. 


\subsection{Interventions that target impaired drivers who are apprehended but not processed through the courts}

\subsubsection{Indications from the literature}

There is some evidence that individuals who receive a roadside suspension are similar to those who receive a Criminal Code impaired driving conviction. For example, Quaye and Boase (2002) reported that as the number of roadside suspensions increased in a jurisdiction, so did the number of Criminal Code convictions on driving records. In an unpublished study, Vingilis (1983) examined the characteristics of a sample of 3,337 drivers who received a roadside suspension in Ontario in 1982. This sample excluded drivers who were involved in a collision or were charged with a Criminal Code impaired driving offence. They found that over one third of the sample already had a licence suspension-most often for a DWI conviction-on their driver's record. Over a 2.5-year follow-up period, about $19 \%$ of the total sample were convicted of an impaired driving offence-a figure that is similar to recidivism rates observed in drivers convicted of a Criminal Code impaired driving offence (Mann et al., 1991).

\subsubsection{Key informant interviews}

Some, but not all, key informants felt that those who have received an administrative roadside licence suspension (particularly those with multiple administrative offences) should be screened or assessed for substance use problems as well.

\section{KEY POINTS}

- Individuals who are given roadside suspensions are similar to those who are convicted of an impaired driving offence in terms of drinking and driving patterns.

- It is likely that both those who receive a roadside suspension and society will experience the same types of benefits that remedial programs confer.

\subsubsection{Best practices}

The evidence suggested that individuals who are given pre-conviction roadside suspensions resulting from an impaired driving occasion are similar to those who are convicted of an impaired driving offence. Thus, it is likely that both they and society will experience the same types of benefits that remedial programs confer.

\section{Best Practice 9}

Individuals who receive pre-conviction roadside suspensions for impaired driving should be considered for referral to assessment and participation in remedial programs. 


\subsection{Governance and training issues}

\subsubsection{Indications from the literature}

DWI offenders share many characteristics with persons with substance use problems (Macdonald and Mann, 1996; Miller and Windle, 1990) which suggests that programs that aim to address their substance use problems should be placed in the hands of trained addictions professionals operating from a behavioural health perspective. This means an emphasis on individual responsibility and the use of science-based knowledge and techniques to bring about behavioural change through self-initiated individual activities that result in abstinence or less harmful substance use behaviours. A variety of alternative governance models have, however, been developed (Mann et al., 1997). Thus, in Canada, responsibility for various portions of programs rests with provincial addictions agencies, health ministries, transportation ministries or private sector service providers. In the United States, programs are often regulated and managed by an agency with a state mandate to provide impaired driver programs and to ensure that programs meet state-determined standards (e.g. Mississippi, New Jersey). These agencies often contract with other agencies to provide programs in specific areas. In some US jurisdictions, where only education programs are provided to some DWI offenders, there is little regulation of programs and the situation approximates that of a free market, with providers competing on the basis of such factors as price and length of program.

\section{KEY POINTS}

- Effective remedial programs for convicted DWI offenders require a behavioural health perspective and an orientation consistent with addictions treatment.

- Programs that address DWI substance use problems should be placed in the hands of trained addictions professionals operating from a behavioural health perspective, who are given ongoing training to maintain their skills and acquire effective new techniques.

\subsubsection{Key informant interviews}

Generally, key informants recommended that the level of programmer training differ between those delivering education programs and those delivering treatment/rehabilitation programs. It was felt that those delivering education programs should have adult education and group facilitation skills, while those involved in treatment and rehabilitation should be trained addictions counsellors/clinicians with particular training in DWI-related issues. Personal credibility, being a resource to the community and having role models from the recovering community were also mentioned.

Several key informants identified the need for ongoing, annual training to address issues such as updated information on program applications and quality assurance. Several key informants indicated that Motor Vehicle Registration staff could benefit from training on remedial programs so they would understand that perspective. 


\subsubsection{Best practices}

The evidence suggests that effective remedial programs for convicted impaired drivers require a behavioural health perspective and an orientation consistent with addictions treatment. This means an emphasis on individual responsibility and the use of science-based knowledge and techniques to bring about behavioural change through self-initiated individual activities that result in abstinence or less harmful substance use behaviours.

\section{Best Practice 10}

Remedial programs should be located in an environment in which a behavioural health perspective and treatment orientation are well established and can be maintained.

Key informants indicated that individuals who provide remedial services to convicted impaired drivers need to have skills in adult education, group facilitation and addictions counselling. These skills are typically found in individuals who have been trained in, or have acquired skills in, the addictions field.

\section{Best Practice 11}

Those providing remedial services to DWI offenders should be trained in substance use issues, and in adult education (particularly those delivering educational interventions) and group facilitation (particularly those delivering more therapeutic interventions).

There are many remedial programs for convicted impaired drivers in Canada and the number of these programs is likely to increase over time.

\section{Best Practice 12}

Those providing remedial measures programs to convicted impaired drivers should be supported in accessing provincial or national training opportunities on an annual or biennial basis.

The key informants indicated that ongoing training is required for professionals to maintain their skills and acquire effective new techniques. 


\subsection{Relationships between DWI programs and licensing authorities}

\subsubsection{Indications from the literature}

There are two general models in which treatment and rehabilitation programs for convicted drinking drivers have been implemented. The first model can be termed the judicial model, in which attendance at a treatment or rehabilitation program is required by the courts. Under this model, judges assign convicted offenders to programs at the time of sentencing and the courts assume responsibility for ensuring that programs are completed. Often, program attendance is a condition of probation, and those who do not attend or do not successfully complete the program may be considered in breach of probation. Under this model, vehicle registration departments have very little contact with treatment and rehabilitation services. This model was previously common in Canada, and is still very common in the United States (Century Council, 1997; Stoduto et al., 1998).

Secondly, there is an administrative model, in which a licensing agency requires an offender to complete an education or treatment program prior to reinstatement of the driver's licence. This model is used in most jurisdictions in Canada. It is generally considered to be superior and more efficient than the judicial model because it ensures that all offenders complete an education or treatment program prior to licence reinstatement. It also reduces the likelihood that courts will use a reduced licence suspension as an incentive to encourage offenders to

\section{KEY POINTS}

- The administrative model, in which a licensing agency requires an offender to complete an education or treatment program prior to reinstatement of the driver's licence, is used in most jurisdictions in Canada.

- The administrative model is generally considered to be superior and more efficient than the judicial model as it ensures that all offenders complete an education or treatment program prior to licence reinstatement.

attend programs. This model requires treatment and rehabilitation services to communicate with driver licensing authorities, particularly when offenders begin and complete programs. In some provinces, programs are actually managed by driver licensing agencies (Stoduto et al., 1998).

\subsubsection{Key informant interviews}

In most jurisdictions, but not all, the administrative model is in place; this means that the decision regarding licence reinstatement is made by the driver licensing authority and it is the responsibility of the offender to meet any requirements for licence reinstatement. One key informant noted that prior to implementation of the administrative model, when legal and other sanctions were court-ordered, the onus was often on the probation officer rather than the offender to find the appropriate education or treatment service or other services. 
All respondents recommended clarity regarding roles and responsibilities, and good communication between the treatment/rehabilitation sector and driver licensing offices and/or the justice system (e.g. regular meetings, provincial coordinating body). Several raised concerns about offenders being "caught in the middle" when communication is unclear. Key informants also indicated that offenders need to be clear about their responsibilities and reporting requirements. Manitoba was identified as a jurisdiction that had clear protocols (e.g. the Addictions Foundation of Manitoba [AFM] working for the client and the motor vehicle registration office dealing with the enforcement aspect). The Manitoba respondent emphasized that the provincial justice department always involves AFM and the motor vehicle licensing authority in any discussion of proposed changes to DWI legislation and that AFM works very closely with the motor vehicle registration office.

Several key informants raised the issue of offenders "shopping around" for a jurisdiction with less onerous requirements in terms of education/treatment and that it would be helpful to have mechanisms for information exchange between jurisdictions on driver history and remedial requirements. Many key informants mentioned the need for national standards or standardization between jurisdictions.

Most, but not all key informants indicated that they were not concerned with confidentiality about the nature of the information being transmitted to licensing authorities. Most intervention programs provide standardized and basic information to the motor vehicle registration office regarding whether the client has met requirements. They will also identify any concerns regarding future substance use issues. Some jurisdictions use risk levels and some concerns were raised regarding their interpretation by motor vehicle registration offices and issues of confidentiality and liability in their interpretation. One key informant raised the issue of risk levels for drugs other than alcohol needing to be developed.

The issue of DWI programs being able to proactively contact those convicted of DWI offences was not supported by most key informants. However, the issue was raised in the context of offenders being unaware of the requirements for assessment and intervention or leaving it until the last moment in terms of the licence suspension period. One key informant recommended that programs have access to conviction information and driver history in order to follow up with clients who are not complying with program attendance requirements, while another suggested that all those arrested for DWI should be required to go through a program whether or not they decide to get their licence back.

In this context, some key informants mentioned the issue of enforcement and that there was little likelihood that offenders driving while under suspension would be caught, particularly in rural areas. One key informant in particular felt that much greater levels of enforcement in terms of detecting impaired drivers were required to reduce DWI offences. Several key informants also mentioned the need for increased public awareness about the consequences of DWI in terms of legal and other sanctions. 


\subsubsection{Best practices}

Preceding sections have made it clear that, to achieve the maximum impact on traffic safety, all impaired driving offenders should complete a remedial measures program (instead of relying on the discretion of the courts to refer to programs those who they think would benefit). The research indicates that maximum safety benefits, in terms of reduced collisions, are achieved when all offenders are required to complete a remedial requirement as a condition of relicensing, as opposed to the situation where the court determines who is and who is not suitable for a remedial program.

\section{Best Practice 13}

Remedial programs should be operated using an administrative model, where program completion is a requirement for relicensing.

One possible model is for the licensing authority to supervise or run remedial programs themselves. However, the conflicts between the "administrative culture" of a licensing authority and the "therapeutic culture" required in a remedial program are likely to be substantial. The balance of expert opinion is that there needs to be a separation between the administration of licence suspensions by the licensing authority and the provision of remedial programming.

\section{Best Practice 14}

Remedial programs should be operated by an agency other than the licensing authorities.

One issue that arose is that of communications between licensing authorities and remedial program providers. The key informants indicated that remedial programs require information from licensing authorities to make important decisions about clients, and licensing authorities require information from remedial authorities to make decisions about licence status. In addition, clients need to be able to obtain clear information about program requirements and regulations.

\section{Best Practice 15}

There is a need for formal and clear mechanisms for coordination and collaboration between licensing authorities and remedial programs, to ensure reciprocal exchange of information to serve the best interests of clients and the public. 


\subsection{Offender payments}

\subsubsection{Indications from the literature}

A key issue in the provision of remedial programs for convicted impaired drivers is the funding of these services. A variety of models for fee collection are used across Canada, with offenders paying service providers directly in some cases, while in others, program charges are included in relicensing fees. A similar situation exists in the United States (Mann et al., 1997; Stoduto et al., 1998).

Some authors have proposed that there should be some consideration of financial hardship. Mann et al. (1997) recommended against such a policy in Canada, in part because costs were lower than in jurisdictions that had financial hardship provisions (mostly American jurisdictions), and because these costs themselves can serve as a deterrent to drinking and driving.

\subsubsection{Key informant interviews}

There was support from the majority (but not all) of the key informants that DWI screening/ assessment and education/treatment programs should be subject to some measure of cost recovery. Among key informants who supported cost recovery, there was broad support for cost recovery for assessments, but less support for offenders paying for DWI-specific education and treatment interventions. Several key informants raised the issue of clients with low incomes or living on social assistance being unable to pay. Fee payments by instalments were suggested

\section{KEY POINTS}

- A variety of models for fee collection are used across Canada, with offenders paying service providers directly in some cases, while in others, program charges are included in relicensing fees.

by one key informant and several mentioned the need to keep payments at a reasonable level, otherwise it will deter participation. Key informants were also clear that the principle of cost recovery applied specifically to those services that focus on substance use and driving, and did not extend to addictions treatment services.

Generally, key informants supported payment of costs up front. However, the issue of whether paying up front might deter participation was raised by several key informants. One key informant indicated that in his jurisdiction, payment is not made until the client applies for licence reinstatement; he endorsed this as a method that increases the "show-rate" for assessment and intervention.

As noted earlier for education/treatment interventions, key informants recommended that cost-recovery measures be standardized between jurisdictions. Information on program costs, including those borne by program participants, is available in Section 6 of this report, Inventory of Canadian DWI Programs. 


\subsubsection{Best practices}

The issue of who should pay for remedial programs has been addressed in several ways in different jurisdictions. However, over the years an emerging consensus has been that the clients should bear at least some of the costs for these services. This has occurred for several reasons, including constraints on public spending and an effort to reinforce the deterrent effect of an impaired driving conviction and associated costs. The key informants have indicated support for cost recovery for these remedial programs. It should be clarified, though, that costs recovered are for the DWI remedial programs specifically, and not for addictions treatment costs that may occur if individuals are referred to that system. Thus, it is recommended that costs for remedial programs for convicted impaired drivers be financed at least in part by user fees.

Program costs, in particular for longer or more intensive programs, can become expensive for offenders. The key informants indicated that it is important to find means to reduce the financial burden for offenders who may be assigned to more expensive program alternatives, or who lacked the financial resources to pay program costs. Several jurisdictions have introduced blended fees for offenders, where costs for all programs are covered by one set fee. While this may increase costs for clients who are in lowcost programs, it reduces the difficulties experienced in meeting fee requirements by those assigned to longer or more intensive programs, and it also allows more intensive programs to be introduced for those who may need them. Because treatment program fees are likely to be small in comparison with other costs associated with licence reinstatement (e.g. licence fees and increased insurance costs), these are not likely to be a major barrier to treatment engagement.

\section{Best Practice 16}

Measures should be taken to reduce the financial burden for offenders, particularly those who are assigned to more expensive program options. This could include applying a single blended fee for all clients, or providing some form of financial assistance for low-income clients. 


\subsection{Program evaluation and research}

\subsubsection{Indications from the literature}

Program evaluation encompasses a variety of activities and processes designed to show the extent to which programs are needed, are conceptually sound, are adequately resourced, are implemented as planned and are cost-effective. Evaluations provide information on the need for a program or program component, and can support accountability, program development and resource allocation decisions. Although closely related, when the primary aim of a program evaluation is to create new knowledge, it may be more properly referred to as research.

Canadian researchers were among the first to document the elevated crash risk associated with driving while impaired by alcohol and among individuals with alcohol use problems (e.g. Schmidt, Smart and Popham, 1963). They were also among the first to provide information on individuals convicted of a drinking-driving offence that proved crucial to the development of successful remedial programs for drinking drivers (e.g. Vingilis, 1983). Several influential evaluations of Canadian programs, conducted in the 1970s and 1980s, showed them to be effective and stimulated further program development (Health Canada, 1997; Mann et al., 1994; Vingilis, Adlam and Chung, 1981; Whitehead, Hulton and Markovsky, 1984; Zelhart, Schurr and Brown, 1975).

Evaluations of Canadian remedial measures programs have provided important insights into the ways these programs operate. In Manitoba and Alberta, evaluations have pointed to the effective-

\section{KEY POINTS}

- Canadian researchers were among the first to document the risk associated with driving while impaired by alcohol and to provide information crucial to the development of successful remedial programs.

- Several influential evaluations of Canadian programs showed the remedial programs to be effective and stimulated further program development.

- There is a need for more extensive evaluation activities that can contribute to quality improvements, innovations and decisions about resource allocation. ness of programs in meeting needs of participants (Health Canada, 1997; Parsons, Wnek and Huebert, 1993). In Ontario, evaluations have demonstrated that the provincial program has been implemented with a high level of consistency and quality across 28 provider sites (e.g. Chipperfield and Mann, 2000; Shuggi et al., 2002) and that the assessment instrument used in the province demonstrates adequate psychometric properties (Flam-Zalcman, Chipperfield and Mann, 2002). In Quebec, evaluation research has described important characteristics of individuals who complete a program assessment (Boudreault, Brassard and Gagnon, 2002) and characteristics of individuals who are non-adherents in mandatory programs (Brown et al., 2002).

However, it is clear that evaluation has not been consistently supported over the years in this country. Frequently, programs have had few resources for evaluation activities, except those that generate basic information needed for 
program management. Programs have thus had to rely on external sources for funds to carry out other evaluation activities. This has not facilitated the kind of sustained evaluation activities necessary to ensure accountability, innovation and high quality programming.

\subsubsection{Key informant interviews}

In the context of describing programming in their jurisdictions, several key informants identified the need for evaluation, and the lack of resources to do this. There were several suggestions that the federal government should develop evaluation criteria that could be used across the country, and identify model Canadian programs. The need for more Canadian research was also expressed. Research on effective client matching tools, different assessment and treatment approaches, the effectiveness of education programs, research on programming for chronic repeat offenders and mandatory treatment were all mentioned.

Key informants generally agreed that DWI recidivism (as measured by incidents that come to the attention of the police, such as 24-hour suspensions and youth violating zero tolerance), and broad client outcomes should both be monitored. Several key informants identified the need to follow up with offenders after licence reinstatement. Several key informants also identified the need for research on offenders who do not apply for licence reinstatement and on the proportion who drive without a licence, and for how long.

Though key informants did not identify specific best practice mechanisms for quality enhancement, they did describe mechanisms in their own jurisdictions, which included using standardized assessment and interventions across a jurisdiction, monitoring program delivery in terms of wait times for assessment and program entry, regular program management meetings, and annual training.

\subsubsection{Best practices}

Program evaluation and research are necessary for program accountability, program development and rational resource allocation. Key informants have identified a strong need for program evaluation and research.

\section{Best Practice 17}

Evaluation should be an integral part of any remedial measures program.

Funding for program evaluation and research has been very inconsistent over the years in this country. To maintain these activities, they should be supported on an ongoing basis as part of core program activities, and budgeted accordingly.

\section{Best Practice 18}

Program evaluation and research costs should be built into program budgets.

Basic program monitoring activities are generally common. However, key informants identified the need for more extensive evaluation activities that can contribute to quality improvements, innovations and decisions about resource allocation.

\section{Best Practice 19}

More emphasis should be placed on quality assurance, and studies of the cost-effectiveness of programs and their component parts. 


\section{Concluding Comments}

\section{4}

Many important steps have been taken to address the needless deaths and injuries caused by impaired driving in Canada, and the advancement of remedial programs for convicted offenders has been a very important development in this process. The research evidence reviewed in this report provides solid support for their continued use. This research and expert opinion also provide valuable insights and guidance on ways in which these programs can be most usefully implemented and organized. These best practices have a reasonably solid research and experiential base.

However, the available evidence and experience were not able to address all of the issues of concern to this report. These issues included whether or not individuals charged or convicted of an offence not related to alcohol or drug use should be required to complete a remedial program; whether or not programs should be gender specific; and the means by which Canada's ethnoculturally diverse population can be best served by remedial programs. While the evidence provides some guidance on screening tools, there is a need for more research to identify clearly superior instruments or procedures.

Beyond these issues, there are likely to be other challenges that these programs will face in the future. Due to greater public attention and

\section{KEY POINTS}

- This report demonstrates that there is solid support for the continued use of DWI offender remedial programs.

- This study has also pointed to gaps in current processes, knowledge and research that need to be explored: 1) whether programs should be gender specific or age specific; 2) how best to serve Canada's ethnoculturally diverse populations; 3) which screening tools may be superior in identifying levels of substance use problems; 4) how to respond to the needs of those convicted of drug-impaired driving; 5) how to promote high standards of effective and efficient programming and program evaluation across Canada.

improved detection methods, it is probable that there will be a need to respond effectively to individuals referred to remedial programs because of drug-impaired driving (e.g. prescribed medications and cannabis), and due to offences that do not explicitly involve alcohol or drugs (e.g. dangerous driving). In the absence of clear direction on these issues, it may be most appropriate for program providers to respond to these situations based on local needs, opportunities and resources. These unresolved issues and challenges also point to important areas for further investigation. 
Nearly all key informants expressed a desire for a national perspective on remedial programs. Several identified the need for greater standardization between provinces/territories with respect to remedial programming, client costs and additional penalties under highway traffic acts. This would assist in maintaining high standards of programming nationally and would also be particularly valuable in those cases where an individual residing in one province is required, by virtue of an offence committed in another province, to meet the remedial program requirements of that province. National training and workshop opportunities for program providers were also recommended. These would provide valuable opportunities for providers in different regions to obtain the most recent information on effective program initiatives. As well, recommendations for national standards for research and program evaluation were also made. These could include guidelines for quality assurance and cost-effectiveness activities. They might also identify the most pressing areas for research to develop and evaluate new program initiatives.
It is widely acknowledged that successes in reducing drinking and driving in this country have been the result of a broad and sustained mix of measures by governments and nongovernmental groups. Remedial programs are an important element in these efforts to reduce the deaths and injuries caused by impaired drivers in Canada. As reflected in this report, there is much information available to guide the development, implementation and operation of these programs. There is a need for still more insight into effective practices for delivering DWI remedial programming, which will be best served by increased national linkages and the same attention to quality that has characterized Canadian efforts over the past four decades. 


\section{Best Practice Statements}

\section{Remedial education and treatment programs:}

1. Remedial programs should occupy an integral place in a comprehensive impaired driving countermeasure program. Participation in such programs should be a condition of licence reinstatement for all persons convicted of an impaired driving offence.

2. Remedial programs should also be an integral part of comprehensive efforts to reduce driving while impaired by drugs other than alcohol. Participation in such programs should be a condition of licence reinstatement for all persons convicted of a drug-related driving offence.

\section{Different types of remedial interventions for different types of DWI offenders:}

3. Comprehensive remedial programs for convicted impaired drivers should incorporate at least two levels of intervention for individuals with differing levels of substance use and related problems.

4. All programs for convicted DWI offenders should incorporate both educational and therapeutic activities, regardless of program length.

5. Mandatory clinical follow-up after licence reinstatement should be required for all DWI offenders sent to remedial programs.

\section{Identification issues:}

6. All convicted DWI offenders should complete a screening/assessment process to inform decisions about the most appropriate level or type of intervention.

7. Instruments that have been shown to be of value in assessing alcohol and drug use problems and recidivism risk should form part of the screening procedure. The performance of these instruments should be monitored on an ongoing basis.

\section{Programs that combine treatment with other measures:}

8. Remedial programs should supplement, not replace, licensing actions. 


\section{When DWI offenders are not processed through the courts:}

9. Individuals who receive pre-conviction roadside suspensions for impaired driving should be considered for referral to assessment and participation in remedial programs.

\section{Governance and training issues:}

10. Remedial programs should be located in an environment in which a behavioural health perspective and treatment orientation are well established and can be maintained.

11. Those providing remedial services to DWI offenders should be trained in substance use issues, and in adult education (particularly those delivering educational interventions) and group facilitation (particularly those delivering more therapeutic interventions).

12. Those providing remedial measures programs to convicted impaired drivers should be supported in accessing provincial or national training opportunities on an annual or biennial basis.

\section{Relationships between DWI programs and licensing authorities:}

13. Remedial programs should be operated using an administrative model, where program completion is a requirement for relicensing.

14. Remedial programs should be operated by an agency other than the licensing authorities.

15. There is a need for formal and clear mechanisms for coordination and collaboration between licensing authorities and remedial programs, to ensure reciprocal exchange of information to serve the best interests of clients and the public.

\section{Payment Structures:}

16. Measures should be taken to reduce the financial burden for offenders, particularly those who are assigned to more expensive program options. This could include applying a single blended fee for all clients, or providing some form of financial assistance for low-income clients.

\section{Program evaluation and research:}

17. Evaluation should be an integral part of any remedial measures program.

18. Program evaluation and research costs should be built into program budgets.

19. More emphasis should be placed on quality assurance, and studies of the costeffectiveness of programs and their component parts. 


\section{Inventory of Canadian DWI Programs}

This is an inventory of educational and therapeutic remedial programs in Canada, as of 2002, for people charged with or convicted of alcohol- or drug-related driving offences. All jurisdictions have a DWI program in place with the exception of the Northwest Territories, Nunavut and Yukon.

All programs are provincial in scope except for the province of British Columbia. The Quesnel Addictions Services DWI Program is a regional program serving the municipality of Quesnel and surrounding areas. Saskatchewan has two DWI programs. The Safe Driving Program is offered in all 12 Regional Health Authorities. It includes an educational component, screening and assessment, and referral to a recovery program through Clinical Services. The second program, the St. Louis Impaired Driver Treatment Program, is a two-week residential program for persons convicted of a repeat DWI offence. Most clients are mandated to this program by the Corrections Branch.

\section{List of Programs from East to West}

1. Newfoundland and Labrador:

Think First - A Program About Drinking and Driving

2. Prince Edward Island:

Driver Rehabilitation Course

3. Nova Scotia:

Addiction Services DWI Program

4. New Brunswick:

Auto Control and Auto Control Plus

5. Québec:

Programme sur l'évaluation de la compatibilité du comportement des personnes relativement à la consommation d'alcool ou de drogue, avec la conduite sécuritaire d'un véhicule
6. Ontario:

Back on Track: Ontario's Remedial

Measures Program for Impaired Drivers

7. Manitoba:

Addictions Foundation of Manitoba's

Impaired Drivers' Program

8. Saskatchewan:

Safe Driving Program; Impaired Driver Treatment Program

9. Alberta:

Planning Ahead/Impact

10. British Columbia:

Quesnel Addictions Services - DWI

Program 


\section{Newfoundland and Labrador}

Program:

Address:

Contact:

Telephone:

Fax:

E-mail:

Website:

Geographic area

served:

Program delivery sites: Bay Roberts, Clarenville, Corner Brook, Gander, Goose Bay, Grand Falls, Labrador City, Marystown, St. Anthony, St. John's and Stephenville. Also offered by correspondence for remote sites.

Program access: $\quad$ Condition of re-licensing.

Target group:

Assessment/ screening tools:

Treatment setting: $\quad$ Not specified

Individual session: No

\section{Think First - A Program About Drinking \& Driving}

Newfoundland and Labrador Safety Council

DWI Program

Regatta Plaza

84 - 86 Elizabeth Avenue

St. John's, NL A1A 1W7

Marliese Janes, President

(709) 754-0210

(709) 754-0010

info@safetycouncil.net

www.safetycouncil.net

Provincial
Those given one or more 12-24-hr. suspension;

First offenders (convicted).

Clients with two or more convictions since 1995 are required to have an Alcohol Assessment completed by Addictions Services, the Department of Health. 
Group session: $\quad$ One session - four hours. Offered once a month in St. John's, once every two months outside St. John's. The program is educational in focus. There are five components to the course:

Session 1 - Introductory section examines pre-course knowledge and beliefs;

Session 2 - Takes a look at the Criminal Code, Highway Traffic Act and Conditions for Reinstatement;

Session 3 - Impairment - the effects of alcohol on the body (BAC) and on driving skills;

Session 4 - Questions and Answers designed to help clients gain control and plan ahead;

Session 5 - Closure and distribution of certificates.

Follow up: $\quad$ Letters

Yearly program $\quad 450$ clients

capacity:

Total DWI budget: Not specified

Client fee: $\quad$ Yes. $\$ 125.35$ (tax included)

Funding sources: $\quad$ Client funded

Type of evaluation: Process evaluation; Quality assurance; Client satisfaction.

Evaluation report: $\quad$ No

Postprogram reporting: No

Suspension reduction: No

Resources used: $\quad$ Think First! Participant Handbook, A Program About Drinking and Driving, published by the Newfoundland and Labrador Safety Council. 


\section{Prince Edward Island}

\section{Program: $\quad$ Driver Rehabilitation Course}

Address: $\quad$ Driver Rehabilitation Course

Highway Safety Operations

P.O. Box 2000

Charlottetown, PE C1A 7N8

Contact: $\quad$ Audrey Mayhew, Safety Officer

Telephone: $\quad$ (902) 368-5214

Fax: $\quad$ (902) 368-5236

E-mail: $\quad$ ammayhew@gov.pe.ca

Website: www.gov.pe.ca

Geographic area Provincial

served:

Program delivery sites: Program is offered in Charlottetown and Summerside three times per year and in Montague twice per year.

Program access: $\quad$ Mandated

Target group: $\quad$ First offenders (convicted); Second offenders (convicted); If three or more convictions, clients are automatically referred to addiction services.

Assessment/ screening tools:
Any driver convicted of two lifetime DWI offences is referred to the Driver Rehabilitation Course for a Driver Risk Assessment-a computerized screening tool. Following the assessment, they may be referred back to the Driver Rehabilitation Course or require further assessment, possibly leading to treatment at an addictions facility.

Treatment setting: Outpatient. Course led by a safety officer from the Highway Safety Branch. Individual session: $\quad$ No 
Group session:

Follow up:

Yearly program

capacity:

Total DWI budget: No separate budget.

Client fee:

No

Funding sources: $\quad$ Government $-100 \%$

Type of evaluation: Client satisfaction.

Evaluation report: $\quad$ No

Postprogram reporting: Yes, to the Ministry of Transportation.

Suspension reduction: No

Resources used: $\quad$ Film: Victims of the Crime. This locally produced film features interviews with victims and relatives. Other films include: What Everyone Should Know About Alcohol; and Driving and the Law. 


\section{Nova Scotia}

Program:

Address:

Contact:

Telephone:

Fax:

E-mail:

Website:

Geographic area served:

Program delivery sites: The DWI program is delivered by the District Health Authorities in the following communities: Antigonish, Dartmouth/Halifax, Kentville, Lunenburg, Pictou, Springhill, Strait Richmond, Sydney, Yarmouth.

Program access: $\quad$ Not specified

Target group:

Assessment/ screening tools:

Treatment setting:

\section{Addiction Services/Drug Dependency DWI Program}

Cape Breton District Health Authority and

Nova Scotia Department of Health

P.O. Box 640

115 Alexandra Street

Sydney, NS B1P 6H7

Everett Harris, Director

(902) 563-2060

(902) 563-2059

eharris@addictionservices.ns.ca

www.addictionservices.ns.ca

Provincial Guysborough Antigonish Strait Health Authority
Those issued a 90-day administrative licence suspension; First offenders (convicted); Multiple offenders (convicted).

SASSI; clinical interview; collateral information; other measures at clinician's request.

Outpatient. Educational and therapeutic focus led by addictions counsellors. Client's session schedule is dependent upon the assessment. 
Individual session: $\quad$ Yes

Group session: $\quad$ Yes. Maximum size of group-20 clients.

Follow up: $\quad$ Discretionary. Booster sessions; letters; interviews; telephone follow-up.

Yearly program Not specified

capacity:

Total DWI budget: Not specified

Client fee: $\quad \$ 350.00$ for assessment only.

Funding sources: $\quad$ Government $-95 \%$

Clients $-5 \%$

Type of evaluation: Client satisfaction

Evaluation report: Not specified

Postprogram reporting: Yes. Must report to the Registry of Motor Vehicles.

Suspension reduction: No

Resources used: Not specified 


\section{New Brunswick}

Program:

Address:

Contact:

Telephone:

Fax:

E-mail:

Website:

Geographic area

served:

\section{Auto Control and Auto Control Plus}

Centre for Education and Research in Safety

P.O. Box 5221

Shediac, NB E4P 8T9

J.E. Louis Malenfant, President

(506) 532-2501, 1-800-665-1107 (to register)

(506) 532-1453

cers@nb.sympatico.ca, jelm@cers-safety.com

http://www.cers-safety.com

Provincial

Program delivery sites: Auto Control (for 1st offenders): Bathurst, Campbellton, Edmundston, Fredericton, Grand Falls, Miramichi, Moncton, Richibuctou, Sackville, St. Stephen, Saint John, Sussex, Tracadie, Woodstock.

Auto Control Plus (for repeat offenders): Bathurst, Fredericton, Grand Falls, Miramichi, Moncton, Saint John, Tracadie.

Program access: $\quad$ Condition of re-licensing.

Target group: $\quad$ First offenders (convicted); Multiple offenders (convicted).

Assessment/ SASSI, Inventory of Drinking Situations (ARF), Alcohol and Major Life screening tools: $\quad$ Areas Inventory, Alcohol Control Knowledge Inventory, Relationships Improvement Checklist, MAST, Traffic Safety, Risk Taking Assessment (experimental) and others as needed.

Treatment setting: Outpatient. Group and individual sessions led by masters and doctoral level addictions counsellors, psychologists, social workers and guidance counsellors. 
Individual session: Individual sessions are offered upon exception.

Minimum three hours plus additional sessions if required.

Auto Control: A program for first-time DWI offenders. Offers both assessment and education. The program teaches participants about DWI and its cost to society, and about alcohol and its effects on behaviour. It also teaches self-management techniques and enlists the help of significant others and professionals.

Auto Control Plus: A program for repeat DWI offenders.

Group session:

Maximum size of group is 18 clients and six to eight in the subgroups for the half-day session. Minimum three and one-half hours up to a full weekend.

Auto Control: Same as for individual sessions. Also includes the presentation of a 17-minute video which gives an overview of the program and covers: a) the negative impact of DWI on society, on the victims and on the offenders, and b) the means for convicted offenders to avoid impaired driving.

Auto Control Plus: A victim's panel and the presence of a significant other to conclude the program is an important feature of the Auto Control Plus Program. Audiovisual displays, modelling, and practice are employed to teach problem solving, stress management techniques and self-control training. Participants are removed from their daily routine for a weekend to examine the consequences of their substance use on themselves and their family. The program is designed to increase the likelihood that participants will seek treatment through motivation, knowledge about mood-altering substance, self-awareness of personal health status, knowledge about treatment efficiency and availability, and familiarity with the treatment process.

Follow up: $\quad$ Minimum of one scheduled within one month.

Letters and telephone follow-up. Results of the assessment will be mailed to each program participant. Telephone follow-up will be done for select cases.

Yearly program Approximately 1,200

capacity:

Total DWI budget: $\quad$ Not specified. 
Client fee:

Funding sources:

Type of evaluation:

Evaluation report:
First offenders pay $\$ 195$; repeat offenders pay $\$ 435$.

$$
\text { Clients }-100 \%
$$

Client satisfaction; quality assurance; process evaluation.

Auto Control and Auto Control Plus programs now emphasize evaluation of DWI participants.

SASSI and a Traffic Safety Risk Assessment have been evaluated, as part of the programs, on an experimental basis.

Postprogram reporting: Yes. Must report to the Department of Public Safety.

Suspension reduction: No

Resources used: $\quad$ Auto Control: A Program to Address Lifestyle Issues Related to Driving While Impaired (1992)

(First offender program, also available in French).

Auto Control Plus: A Program to Address Lifestyle Issues Related to Driving While Impaired (1992) (Repeat offender program, available in French).

Auto Control: A 17-minute video to complement the Auto Control Programs (available in French) (1994).

L'effet de matériel pédagogique portant sur l'acquisition de connaissances saines, d'habiletés efficaces et de comportements pro-actifs pour contrer l'usage d'alcool par les adolescents de 13 et 14 ans (1999), submitted to the Canadian Brewers Association.

Tiens-Toi Debout! Evaluation d'une trousse pédagogique pour prévenir l'usage abusif et illégal de l'alcool chez les adolescents de 13 et 14 ans (2000). This is a web-based educational program to sensitize and dissuade Canadian pre-teens from consuming alcohol.

You can visit the website at www.schoolnet.ca. 


\section{Quebec}

Program:

Address:

Contact:

Telephone:

Fax:

E-mail:

Website:

Geographic area served:

Program delivery sites: Amos, Baie-Comeau, Beauceville, Chandler, Drummondville, Hull, Îles de la Madeleine, Jonquière, Laval, Mont-Laurier, Montréal, Québec, Rimouski, Rivière-du-Loup, Robertville, Saint-Hubert, Saint-Jérome, Sept-Îles, Sherbrooke, Ste-Anne des Monts, St-Charles-Borromée, St-Philippe de Laprairie, St-Romuald, Trois-Rivières, Victoriaville.

Program access: $\quad$ Condition of re-licensing.

Target group:

Assessment/ screening tools:
Programme sur l'évaluation de la compatibilité du comportement des personnes relativement à la consommation d'alcool ou de drogue, avec la conduite sécuritaire d'un véhicule

Fédération Québécoise des centres de réadaptation pour personnes alcooliques et autres toxicomanes (FQCRPAT)

204 Notre-Dame ouest, Pièce 350

Montréal, QC H2Y 1T3

Michel Proulx, Manager

(514) $287-9625$

(514) 287-9649

fqcrpat@fqcrpat.qc.ca; mproulx@fqcrpat.qc.ca

www.fqcrpat.org

Provincial 
Treatment setting: Outpatient. Individual session only led by addictions counsellors, psychologists and nurses all accredited to do assessments by FQCRPAT.

Individual session: $\quad$ Yes. The number of sessions vary between one and three; each session is approximately one and one half hours. A treatment plan is developed that encourages the individual to reflect upon 1) driving while impaired, and 2) his or her alcohol and drug use.

Group session: $\quad$ No

Follow up: $\quad$ Yes. One, one hour face-to-face interview in six months.

Yearly program $\quad 2,500$ to 10,000

capacity:

Total DWI budget: Not available

Client fee: $\quad$ Yes. Three different assessments. The price varies with each.

Funding sources: $\quad$ Clients pay $100 \%$ of costs.

Type of evaluation: Client satisfaction

Evaluation report: $\quad$ Yes

Postprogram reporting: Yes, to the Société de l'Assurance Automobile du Québec

Suspension reduction: No

Resources used: $\quad$ Not specified 


\section{Ontario}

$\begin{array}{ll}\text { Program: } & \text { Back on Track } \\ & \text { Ontario's Remedial Measures Program for Impaired } \\ & \text { Drivers }\end{array}$

Address: $\quad$ Centre for Addiction and Mental Health

33 Russell Street, Room 1062

Toronto, ON M5S 2S1

Contact: $\quad$ Rania Shuggi, Manager, Remedial Measures Program

Telephone: $\quad 1(888) 814-5831$

Fax: $\quad$ (416) $595-6735$

E-mail: $\quad$ info@remedial.net

Website: $\quad$ www.remedial.net

Geographic area Provincial

served:

Program delivery sites: Aurora, Barrie, Belleville/Napanee, Bracebridge, Brampton, Brantford, Brockville/Smith's Falls, Burlington, Cornwall, Guelph/Kitchener, Hamilton, Kenora, Kingston, London, North Bay, Oshawa, Ottawa, Owen Sound, Pembroke/Renfrew, Sarnia, Sault Ste. Marie, Stratford, St. Catharines, Sudbury, Thunder Bay, Timmins, Toronto, Windsor.

Program access: $\quad$ Mandated

Assessment/ Research Institute on Addictions Self-Inventory (RIASI); Alcohol screening tools: Dependence Scale (ADS); Drug Abuse Screening Test (DAST).

Treatment setting: Outpatient. Sessions are led by addictions counsellors.

Individual session: $\quad$ Offered for those unable to function in a group setting - with special accommodation. Eight hours-usually one session.

The focus is therapeutic and the session content includes: alcohol education; goal setting; drinking and drug use diary; high-risk situations; formulating an action plan; coping skills training; readings and written assignments. 
Group session:

Follow up:

Yearly program

capacity:

Total DWI budget: Funding based on client fees.

Client fee:

Funding sources: $\quad$ Clients $-100 \%$

Type of evaluation: Client satisfaction; content evaluation; assessment consistency.

Evaluation report: $\quad$ Back on Track, Report No.1, analysis of client satisfaction data, collected to January 2000. Centre for Addiction and Mental Health.

Postprogram reporting: The Ministry of Transportation receives results on drivers within 24 hours of their completion of each component (i.e. assessment, education/ treatment, follow-up). Clients must complete all program components to have their licence reinstated.

Suspension reduction: No 
Resources used: $\quad$ Back on Track Assessment and Follow-up Manual;

Education Program Facilitators Manual and Participants Workbook;

Treatment Program Counsellor's Manual and Client Workbook;

Mother's Against Drunk Driving (MADD) Video - Close to Home.

We also acknowledge our debt to the following sources and programs:

Alberta Alcohol and Drug Abuse Commission (1987). Impaired Drivers' Course: Planning Ahead.

Mississippi Alcohol Safety Education Program (1995), Mississippi State University.

Addiction Research Foundation (1996). Drinking, Drugs and Driving: Tips for Driver Educators.

Addiction Research Foundation (1994). Guided self-change for assessment and referral centres.

Structured relapse prevention program (1996). Addiction Research Foundation.

Impaired driver's educational workshop manual (1992), Addictions Foundation of Manitoba. 


\section{Manitoba}

Program:

Address:

Contact:

Telephone:

Fax:

E-mail:

Website:

Geographic area

served:

Program delivery sites:

Program access:

Target group:

Assessment/

screening tools:

\section{Addictions Foundation of Manitoba's Impaired Drivers' Program}

Addictions Foundation of Manitoba (AFM)

1031 Portage Avenue

Winnipeg, MB R3G 0R8

Heather Mitchell, Supervisor

(204) 944-6326

(204) 774-8091

hmitchell@afm.mb.ca

www.afm.mb.ca

Provincial
Brandon, Dauphin, Flin Flon, Gillam, Killarney, Neepawa/Minnedosa, Portage la Prairie, Rossburn, The Pas, Thompson, Winnipeg.

Condition of re-licensing; Mandated.

Those given two or more 24 hour suspensions in a three year period or one 24 hour suspension following an impaired charge in the previous three years;

Those issued a 90-day administrative licence suspension;

First offenders (convicted);

Multiple offenders (convicted);

DWI offence other than alcohol;

DWI offence while using off-road vehicles.

SALCE (Substance Abuse/Life Circumstance Evaluation) and an individual interview by a trained addictions counsellor to complete a counsellor-directed assessment. 
Treatment setting: Community-based and residential sessions led by addictions counsellors.

Individual session: Dependent upon program referral.

Educational Program has no individual session.

High Risk Program is educational in focus and geared to high-risk clients. The session content aims to initiate a contract for involvement, to monitor progress in the program, to work toward awareness, to establish goals re: substance abuse, and to monitor abstinence or modified usage.

Group session: $\quad$ Maximum size of group is 15 .

Education Program for those assessed as having a presumptive substance use problem consists of a one day, eight-hour workshop. This educational program includes awareness of laws and consequences, attitudes of ownership, effects of alcohol and other substances on BAC, separating drinking from driving behaviour, alternative planning, styles and categories of drinking.

High Risk Program for those assessed as being at risk of re-offending due to continued high-risk behaviours or being at risk of dependent involvement: six groups-12.5 hours over approximately six months. The High Risk Program focuses on risk reduction through examining one's use and making plans to implement change in use.

Rehabilitation Program Options is community-based, once a week for three hours for 10 weeks; or daily intensive with five days a week for three weeks plus self-help; or a residential program of 21 to 28 days plus self-help.

Follow up: $\quad$ Although there is no follow-up to the Education Program or the High Risk Program, after-care is available for those clients who complete one of the rehabilitation programs.

Follow-up sessions vary from one to two hours, for rehabilitation four to six sessions.

Yearly program $\quad 2,000$

capacity:

Total DWI budget: $\quad \$ 445,000$ for the assessment, educational workshop and high-risk program. The rehabilitation costs are covered through the agency's regular program budget. Only 15\% of those assessed are referred to the rehabilitation program. 
Client fee:

Funding sources: Clients and government funding.

Type of evaluation: Outcome

Evaluation report: $\quad$ 1997—Comprehensive evaluation conducted by Health Canada;

1999-A comparative analysis by AFM.

Postprogram reporting: If the assessment is court ordered. For all clients, reporting is required to the Division of Driver and Vehicle Licensing of Manitoba and/or occasionally to other provinces and states if the offence occurred outside the province.

Suspension reduction: No

Resources used: $\quad$ Administrative and program manuals. 


\section{Saskatchewan}

\section{Program: Impaired Driver Treatment Program}

Address:

St. Louis Alcoholism Rehabilitation Centre

Impaired Driver Treatment Program

Saskatchewan Health

P.O. Box 220

545 - 1st Street

St. Louis, SK SOJ 2C0

Contact: $\quad$ Roger Zelinski, Director

Telephone: (306) 422-8533

Fax: $\quad$ (306) $422-8488$

E-mail: stlouisrehabctr@sk.sympatico.ca

Website: None available

Geographic area Provincial

served:

Program delivery sites: St. Louis, Saskatchewan

Program access: $\quad$ Mandated

Target group: $\quad$ Multiple offenders (convicted)

Assessment/ SASSI 3.

screening tools:

Treatment setting: $\quad$ Residential, led by addictions counsellors.

Individual session: Two or three one- to two- hour sessions as needed. History, education, behaviour patterns. 
Group session:

Follow up:

Yearly program

capacity:

Total DWI budget: $\quad \$ 750,000$

Client fee:

No

Funding sources: $\quad$ Government $-100 \%$

Evaluation report: $\quad$ No

Postprogram reporting: No

Suspension reduction: No

Resources used: $\quad$ St. Louis Alcoholism Rehabilitation Centre Impaired Driver Treatment Program brochure. 


\section{Saskatchewan (cont'd)}

Program:

Address:

Contact:

Telephone:

Fax:

E-mail:

Website:

Geographic area served:

Program delivery sites: Screening is offered in all 12 Regional Health Authorities and the DWI Course is offered in 22 centres. Other than northern points, the program is set up so that no one has to travel more than 150 kilometres to access services.

Program access:

Target group:

\section{Safe Driving Program}

SGI Driver Licensing

2260, 11th Avenue, 3rd Floor

Regina, SK S4P 0J9

Phyllis Glowatsky, Manager

(306) 775-6180

(306) 569-9631

pglowatsky@sgi.sk.ca

www.sgi.sk.ca

Provincial
Condition of re-licensing; Mandated

Those given one or more 12 to 24 hour suspension;

First offenders (convicted);

Multiple offenders (convicted);

DWI offence other than alcohol;

DWI offence while snowmobiling;

Any driving-related Criminal Code conviction (e.g. leaving the scene of an accident, dangerous driving). 
Assessment/

screening tools:

Treatment setting: Outpatient. Sessions led by addictions counsellors.

Individual session: Approximately four hours over two to four sessions.

The focus of the program is both educational and therapeutic. All clients have individual sessions for screening and are subsequently referred to one of two options: Education through the Drive Without Impairment Course, or to Recovery. If recovery is indicated, a Clinical Services addictions counsellor will develop an individualized treatment plan. The screening process examines the history of the client re: drinking, drugs, family, work, and the legal circumstances regarding the charges. We also screen for substance dependency.

Group session: $\quad$ Schedule varies_depends on site location.

Maximum size of group varies but approximately 12 people.

DWI Course: The DWI education component is a group course designed to educate individuals about the serious problems related to drinking and driving and to distinguish and separate the acts of drinking and driving.

Recovery Program: If a client is screened as chemically dependent, he or she is referred to a recovery program often offered at the same addictions services site as the screening. The recovery program is an individualized plan, recommended by the addictions counsellor, and may include weekly individual or group counselling, assignment to a treatment centre, participation in AA, counselling from other agencies or other actions.

Follow up: $\quad$ One-hour voluntary face-to-face interviews.

Follow-up is always offered but rarely used and it is not mandated.

Yearly program capacity:

Total DWI budget: The DWI budget for the year 2000 was approximately $\$ 1.2$ million provincially for the screening. This allows for approximately three and one-half to four hours per client for screening and assessment and breaks down into \$344 per client. Recovery is through the Health System and does not have a separate budget. 
Client fee: $\quad$ Clients screened to the DWI education program must pay $\$ 150$ each.

Evaluation report: $\quad$ No

Postprogram reporting: No

Suspension reduction: Individuals who have completed the court order and the program may be eligible for a restricted licence for the first half of the suspension period. At this time, they must apply for a provisional licence until the end of the original suspension period. The Ignition Interlock Program allows for early reinstatement of a restricted driver's licence under certain circumstances and with certain requirements.

Resources used: $\quad$ Videos: Truth About Drinking, Disease Concept, Addiction—Getting In, Getting Out;

Educational material on addiction — disease concept, addiction cycle, valley chart;

AA referral as required;

DWI Manual, Safe Driving Program Administrative Manual; Additional resources vary from site to site. 


\title{
Alberta
}

Program:

Address:

Contact:

Telephone:

Fax:

E-mail:

Website:

Geographic area served:

\section{Alberta Impaired Driving Program Planning Ahead/Impact}

\author{
Alberta Motor Association \\ Alberta Impaired Driving Program \\ Administration Centre \\ 10310 - 39A Avenue \\ Edmonton, AB T6J 6R7 \\ Walter Barta, Traffic Safety Coordinator
}

(780) 430-5533

(780) $430-5676$

wbarta@ama.ab.ca

www.ama.ab.ca

Provincial

Program delivery sites: Planning Ahead (first offender course): Barrhead, Bonnyville, Brooks, Calgary, Camrose, Cold Lake, Drayton Valley, Edmonton, Edson, Fort McMurray, Grande Prairie, High Level, High Prairie, Hinton, Lac La Biche, Lethbridge, Lloydminster, Medicine Hat, Peace River, Pincher Creek, Red Deer, Rocky Mountain, St. Paul, Slave Lake, Stettler, Vegreville, Vermillion, Wainwright, Westlock, Wetaskiwin, Whitecourt. IMPACT (repeat offender course): Calgary (3 sites), Claresholm, Edmonton, Grande Prairie.

Program access: $\quad$ Condition of re-licensing.

Target group: $\quad$ Those issued a 90-day administrative licence suspension; first offenders (convicted);

Multiple offenders (convicted);

DWI while boating or snowmobiling is a possible cause for referral but rare.

84 | Best Practices - Treatment and Rehabilitation for Driving While Impaired Offenders 
Assessment/

screening tools:

Treatment setting: Planning Ahead is outpatient; IMPACT is residential.

Sessions are led by addictions counsellors and professional educators with addictions training.

Individual session: $\quad I M P A C T$ : includes one individual interview.

Group session: $\quad$ Maximum size of group is 30.

Planning Ahead: One large group session with some break-out sessions, all educational in focus. This program includes a review of the Criminal Code; laws and regulations; myths about drinking and driving; estimating blood alcohol content (BAC); education about drinking and driving; gaining control; group assignment; action plans.

IMPACT: Nine small group sessions (max. 6 clients) and six large group sessions (max. 30 clients) all scheduled over one weekend. This program includes an introduction; effects of mood-altering drug use; major life areas; individual interviews; Major Life Areas review; level of use; personal empowerment; personal strategies; Alcoholics Anonymous (AA) presentation; video presentation; taking action.

Follow up: $\quad$ No

Yearly program Planning Ahead: 6,000

capacity:

Total DWI budget: Program operates on a user pay scheme with no government funding.

Planning Ahead: \$485,000 for 2002

IMPACT: $\$ 235,000$ for 2002

Client fee:

Planning Ahead: $\$ 115$

IMPACT: \$205

Funding sources: $\quad$ Clients $-100 \%$ 
Type of evaluation: Process evaluation; outcome evaluation.

Postprogram reporting: Yes. For the IMPACT program only, a summary report with a diagnosis and recommendations is produced for all participants. Some clients are required to present this report to the Driver Control Board (DCB). The Board may insist on compliance with the report recommendations.

Suspension reduction: No

Resources used: $\quad$ Planning Ahead: Video—short version of Make Sure It Isn't You; Planning Ahead Handbook; Program Guide.

IMPACT: Video-Make Sure It Isn't You and I'll Quit Tomorrow; info sheets from Alberta Alcohol and Drug Abuse Commossion-ABC's of Drugs and Alcohol Series; Program Guide. 


\section{British Columbia}

Program:

Address:

Contact:

Telephone:

Fax:

E-mail:

Website:

Geographic area served:

Program delivery sites: Quesnel, BC

Program access:

Target group:

Assessment/ screening tools:

Treatment setting:

Individual session:

qas@telus.net

\section{Quesnel Addictions Services-DWI Program}

Quesnel Alcohol and Drug Abuse Association

Driving While Impaired Program

P.O. Box 4043

543 Front Street

Quesnel, BC V2J 3J2

Bea Randall, Executive Director

(250) 992-5189

(250) $992-2657$

None available

Municipal area of Quesnel and surrounding areas.

Referral by Probation Officers.

First offenders (convicted);

Multiple offenders (convicted).

MAST; DAST; SASSI

Outpatient. Sessions led by addictions counsellors.

One one-hour session; additional weekly session can be arranged if needed. Focus is both educational and therapeutic. The individual session includes assessment and consultation which is client-centered. 
Group session: $\quad$ One weekend program (21 hours) offered once per year. We try to schedule participants during their probation period. Maximum size of group is 15 . Focus is educational. Group session content tends to focus mostly on alcohol and drug education; effects of alcohol and drugs; DWI and the law; examination of life areas; RCMP presenters, etc.

Follow up: $\quad$ One 15-minute telephone interview within three months.

Yearly program Approximately 15 clients.

capacity:

Total DWI budget: Approximately $\$ 1,500$ for room rental, food costs, assessments and treatment tools, wages.

Client fee: $\quad$ No.

Funding sources: $\quad$ Government $-100 \%$

Type of evaluation: Client satisfaction

Postprogram reporting: Yes. To the Probation Officer.

Resources used: $\quad$ Videos: Chalk Talk; Addictions—Getting in, Getting Out; Through a Blue Lens; Steer Clear.

Manuals: Most of the program has been adapted from the Impact program manual developed by the Alberta Alcohol and Drug Abuse Commission. 


\section{References}

ADE, Inc. (1986). Substance Abuse/Life Circumstances Evaluation Manual (SALCE). Clarkson, MI: ADE, Inc.

Adlaf, E.M., Mann, R.E. \& Paglia, A. (2003). Drinking, cannabis use and driving among Ontario students. Canadian Medical Association Journal, 168, 565-566.

Alcoholics Anonymous 20 Questions (n.d.) http://www.recoveryresources.org/twenty.html. Accessed 9/3/03.

Applegate, B.K., Langworth, R.H. \& Latessa, E.J. (1997). Factors associated with success in treating chronic drinking drivers: The turning point program. Journal of Offender Rehabilitation, 24, 19-34.

Ball, S.A., Jaffe, A.J., Crouse-Artus, M.S., Rounsaville, B.J. \& O’Malley, S.S. (2000). Multidimensional subtypes and treatment outcome in first-time DWI offenders. Addictive Behaviours: An International Journal, 25, 167-181.

Beirness, D.J., Simpson, H.M. \& Desmond, K. (2003). The Road Safety Monitor 2002: Drugs and Driving. Ottawa: Traffic Injury Research Foundation.

Bohn, M.J., Babor, T.F. \& Kranzler, H.R. (1995). Alcohol Use Disorders Identification Test (AUDIT): Validation of a screening instrument for use in medical settings. Journal of Studies on Alcohol, 56, 423-432.

Boudreault, J., Brassard, A. \& Gagnon, J.P. "Behavioural Assessment of Quebec Drivers Convicted of a Second or Subsequent Impaired Driving Offence Under the Criminal Code". Paper presented at the 14th International Conference on Alcohol, Drugs and Traffic Safety - T2002, Montreal, Aug. 4-9, 2002.

Brown, T., Nadeau, L., Lageix, P., Lepage, M., Tremblay, J. \& Seraganian, P. “Non-Adherents in Mandatory Substance Abuse Evaluation Following a DUI Offense: Their Characteristics and Reasons for Non-Compliance". Paper presented at the 14th International Conference on Alcohol, Drugs and Traffic Safety - T2002, Montreal, Aug. 4-9, 2002.

Canadian Centre for Justice Statistics. (2002). http://www.statcan.ca/english/IPS/Data/ 85F0033MIE.htm. Accessed 12/1/02. 
Cavaiola, A. \& Wuth, C. (2002). Assessment and Treatment of the DWI Offender. New York: The Haworth Press.

C'de Baca, J., Lapham S.C., Liang, H.C. \& Skipper B. J. (2001) Victim Impact Panels: Do They Impact Drunk Drivers? A Follow-Up of Female and Male, First-Time and Repeat Offenders. Journal of Studies on Alcohol, September 2001, 62 (5) 615-620.

C'de Baca, J., Miller, W.R. \& Lapham, S.C. (2001). A multiple risk factor approach for predicting DWI recidivism. Journal of Substance Abuse Treatment, 21, 207-215.

Century Council. (1997). Combating Hardcore Drunk Driving: A Sourcebook of Promising Strategies, Laws and Programs. Washington, DC.

Chang, I., Gregory, C. \& Lapham, S.C. (2002). Review of Screening Instruments and Procedures for Evaluating DWI Offenders. AAA Foundation for Traffic Safety. http://www.aaafoundation.org. Accessed 12/01/02.

Chang, I., Lapham, S.C. \& Wanberg, K.W. (2001). Alcohol Use Inventory: Screening and assessment of first-time driving-while-impaired offenders. I. Reliability and profiles. Alcohol and Alcoholism, 36, 112-121.

Chipperfield, B. \& Mann, R.E. (2000). Back on Track Reports: No. 1. Analysis of Client Satisfaction Data: Data Collected to January 2000. Toronto: Centre for Addiction and Mental Health.

Cimbura, G., Lucas, D.M., Bennet, R.C. \& Donelson, A.C. (1990). Incidence and toxicological aspects

of cannabis and ethanol detected in 1,394 fatally injured drivers and pedestrians in Ontario. (1982-1984). Journal of Forensic Science, 35(5), 1035-1041.

Davies, G.P., Broughton, J., Harland, D.G. \& Tunbridge, R. (undated). “Drink/Driver Rehabilitation Courses in England and Wales". http:||www.se/traf_sak/+2000/404.pdf

DeYoung, D.J. (1997). An evaluation of the effectiveness of alcohol treatment, driver licence actions and jail terms in reducing drunk driving recidivism in California. Addiction, 92(8), 989-997.

Donovan, D.M. \& Marlatt, G.A. (1992). Personality subtypes among driving-while-intoxicated offenders: Relationship to drinking behaviours and driving risk. Journal of Consulting and Clinical Psychology, 50, 241-249.

Donovan, D.M., Queisser, H.R., Salzberg, P.M. \& Umlauf, R. (1985). Intoxicated and bad drivers: Subgroups within the same population of high-risk men drivers. Journal of Studies on Alcohol, 46, $375-382$. 
Donovan, D.M., Umlauf, R.L. \& Salzberg, P.M. (1988). Derivation of personality subtypes among high risk drivers. Alcohol, Drugs and Driving, 4, 233-243.

Dussault, C., Brault, M., Bouchard, J. \& Lemire, A.M. (2002). The contribution of alcohol and other drugs among fatally injured drivers in Quebec: Some preliminary results. In D.R. Mayhew and C. Dussault (eds.) Proceedings of the 16th International Conference on Alcohol, Drugs and Traffic Safety, pp. 423-430. Quebec: Société de l'assurance automobile du Québec.

Flam-Zalcman, R., Chipperfield, B. \& Mann, R.E. (2002). Back on Track Reports: No. 5. Evaluation of the Back on Track Assessment Instrument and Process: Data from 2001. Toronto: Centre for Addiction and Mental Health.

Foon, A.E. (1988). The effectiveness of drinking-driving treatment programs: A critical review. International Journal of the Addictions, 23, 151-174.

Gentiello, L.M., Rivara, F.P., Donovan, D.M., Jurovich, G.J. et al. (1999). Alcohol interventions in a trauma centre as a means of reducing the risk of injury recurrence. Annals of Surgery, 230, 473-480.

Gjerde, H. \& Morland, J. (1988). A two-year prospective study of rearrests for drunken driving. Scandinavian Journal of Social Medicine, 16, 111-113.

Gray, B.T. (2001). A factor analytic study of the Substance Abuse Subtle Screening Inventory (SASSI). Educational and Psychological Measurement, 61, 102-118.

Health Canada (1997a). DWI Repeat Offenders: A Review and Synthesis of the Literature. Ottawa: Minister of Public Works and Government Services. Cat. No. H39-416/1997E.

- - - . (1997b). Evaluation of Addictions Foundation of Manitoba's Impaired Driver's Program. Ottawa. Minister of Public Works and Government Services. Cat. No. H39-415/1997E.

_ _ - . (1999). Best Practices - Substance Abuse Treatment and Rehabilitation. Ottawa: Minister of Public Works and Government Services. Cat. No. H39-438/1998E.

— — - (1998). Canada's Drug Strategy. Ottawa: Minister of Public Works and Government Services. Cat. No. H39-440/1998E.

- - - .(2001a). Best Practices - Fetal Alcohol Syndrome/Fetal Alcohol Effects and the Effects of Other Substance Use During Pregnancy. Ottawa: Minister of Public Works and Government Services. Cat. No. H49-156/1-2001E.

_ - - .(2001b). Best Practices - Treatment and Rehabilitation for Women with Substance Abuse Problems. Ottawa: Minister of Public Works and Government Services. Cat. No. H49-153/2001E. 
- - - .(2001c). Best Practices - Treatment and Rehabilitation for Youth with Substance Use

Problems. Ottawa: Minister of Public Works and Government Services. Cat. No. H49-154/2001E.

_ _ - .(2001d). Best Practices - Concurrent Mental Health and Substance Use Disorders. Ottawa: Minister of Public Works and Government Services. Cat. No. H39-599/2001-2E.

_ - _ .(2002). Best Practices - Methadone Maintenance Treatment. Ottawa: Minister of Public Works and Government Services Cat. No. H49-164/2002E.

Hemmelgarn, B., Suissa, S., Huang, A., Boivin J.F. \& Pinard, G. (1997). Benzodiazepine use and the risk of motor vehicle crash in the elderly. Journal of the American Medical Association, 278, 27-31.

Horn, J.L., Wanberg, K.W. \& Foster, F.M. (1987). Guide to the Alcohol Use Inventory. Minneapolis: National Computer Systems.

Institute of Medicine. (1990). Broadening the Base of Treatment for Alcohol Problems. Washington, DC: National Academy of Science.

Jones, R.K., Wiliszowski, C.H. \& Lacey, J.H. (1996). Evaluation of Alternative Programs for Repeat DWI Offenders. Washington, DC: National Highway Traffic Safety Administration.

Jones, R.K. \& Lacey, J.H. (1999). Final Report: Evaluation of a Day Reporting Center for Repeat DWI Offenders. Washington, DC: National Highway Traffic Safety Administration.

King, M. (1986). At risk drinking among general practice attenders: Validation of the CAGE questionnaire. Psychological Medicine, 16: 213-217.

Kooler, J.M. \& Bruvold, W.H. (1992). Evaluation of an educational intervention upon knowledge attitudes and behaviour concerning drinking-drugged driving. Journal of Drug Education, 22: 87-100.

Lapham, S., C'de Baca, J., Chang, I., Hunt, W. \& Berger, L. (2001). Are drunk-driving offenders referred for screening accurately reporting their drug use? Drug and Alcohol Dependence, 66, 243-253.

Lindeman, H. \& Scrimgemour, W.G. (1999). Driver Risk Inventory (DRI): An Inventory of Scientific Findings. Phoenix, AZ: Behavioral Data Systems, Ltd.

Lucker, G.W. \& Osti, J.R. (1997). Reduced recidivism among first-time DWI offenders as a correlate of pre-trial intervention. Journal of Offender Rehabilitation, 24, 1-17.

MacAndrew, C. (1965). The differentiation of male alcoholic outpatients from non-alcoholic patients by means of the MMPI. Quarterly Journal of Studies on Alcohol, 42, 604-623. 
Macdonald, S. \& Mann, R.E. (1996). Distinguishing causes and correlates of drinking and driving. Contemporary Drug Problems, 23, 259-290.

Macdonald, S., Mann, R.E., Chipman, M.L. \& Anglin-Bodrug, K. "Collisions of Alcohol, Cannabis and Cocaine Clients Before and After Treatment". Paper presented at the 16th International Conference on Alcohol, Drugs and Traffic Safety - T2002, Montreal, Aug. 4-9, 2002.

Macdonald, S., Mann, R.E., Chipman, M.L. \& DeSouza. A. (2003). "Self-Reports of Driving After Use of Alcohol, Cannabis and Cocaine for Substance Abuse Treatment Clients and Population Controls". Unpublished manuscript.

Mann, R. (1992). Effectiveness of DUI treatment and the importance of screening and matching clients to appropriate treatment. In: Drinking and Driving Prevention Symposium. Ontario, CA: Automobile Club of Southern California.

Mann, R.E., Anglin, L., Rahman, S., Blessing, L.A., Vingilis, E.R. \& Larkin, E. "Does Treatment for Substance Abuse Improve Traffic Safety? A Preliminary Evaluation”. Paper presented at the 13th International Conference on Alcohol, Drugs and Traffic Safety. Adelaide, Australia, August 13-18, 1995.

Mann, R.E., Anglin, L., Wilkins, K., Vingilis E.R., Macdonald, S. \& Sheu, W.J. (1994). Rehabilitation for convicted drinking drivers (second offenders); effects on mortality. Journal of Studies on Alcohol, 55, 372-74.

Mann, R., Koski-Jannes, A., Room, R., Mitchell, B., Harrison, S., Stoduto, G. \& Rush, B. (1997). Remedial Programs for Convicted Drinking-Drivers. Part 2: Implementing a Systematic Program in Ontario. Toronto: Addiction Research Foundation.

Mann, R.E., Leigh, G., Vingilis, E. \& De Genova, K. (1983). A critical review on the effectiveness of drinking-driving rehabilitation programs. Accident, Analysis and Prevention, 15, 441-461.

Mann, R.E., Macdonald, S., Stoduto, G., Shaikh, A. \& Bondy, S. (1998). Assessing the Potential Impact of Lowering the Legal Blood Alcohol Limit to $50 \mathrm{mg} \%$ in Canada. Publication No. TR 13321 E. Ottawa: Transport Canada.

Mann, R.E., Stoduto, G., Macdonald, S., Shaikh, A., Bondy, S. \& Jonah, B. (2001). The effects of introducing or lowering legal per se blood alcohol limits for driving: An international review. Accident Analysis and Prevention, 33, 61-75.

Mann, R.E., Vingilis, E.R., Gavin, D., Adlaf, E. \& Anglin, L. (1991). Sentence severity and the drinking driver: Relationships with traffic safety outcome. Accident, Analysis and Prevention, 23, 483-491. 
Marlatt, G.A. \& Miller, W.R. (1984). Comprehensive Drinker Profile. Odessa, FL: Psychological Assessment Resources.

Mayhew, D. R., Brown, S.W. \& Simpson, H.M. (2002). The Alcohol-Crash Problem in Canada: 1999. Ottawa: Transport Canada.

McKnight, A.J. \& Voas, R.B. (1991). The effect of licence suspension upon DWI recidivism. Alcohol, Drugs and Driving, 7, 43-54.

McLellan, A.T., Kusher, H., Metzger, D., Peters, R., Smith, I., Grisson, G. \& Pettinati, H. (1992). The fifth edition of the Addiction Severity Index: Historical critique and normative data. Journal of Substance Abuse Treatment, 9, 199-213.

McMillen, D.L., Adams, M.S., Wells-Parker, E., Pang, M.G. \& Anderson, B.J. (1992). Personality traits and behaviors of alcohol-impaired drivers: A comparison of first and multiple offenders. Addictive Behaviors, 17, 407-414.

Miller, G.A. (1994). The Substance Abuse Subtle Screening Inventory Manual (SASSI). Bloomington, IN. The SASSI Institute.

Miller, B.A. \& Windle, M. (1990). Alcoholism, problem drinking and driving while impaired. In R.J. Wilson and R.E. Mann (eds.), Drinking and Driving, Advances in Research and Prevention, pp. 68-98. New York, NY: The Guilford Press.

Monti, P.M., Colby, S.M., Barnett, N.P., Spirito, A., Rohsenow, D.J., Myers, M., Woolard, R. \& Lewander, W. (1999). Brief intervention for harm reduction with alcohol-positive older adolescents in a hospital emergency department. Journal of Consulting and Clinical Psychology, 67, 989-994.

Mortimer, R.G., Filkins, L.D. \& Lower, J.S. (1971). Court Procedures for Identifying Problem Drinkers: Final Report. Ann Arbor, MI: Highway Safety Research Institute, University of Michigan. DOT Contract FH-11-761.

National Cancer Institute of Canada. (2001). Canadian Cancer Statistics, 2001. Ottawa: National Institute of Cancer.

National Commission Against Drunk Driving. 2002. http://www.ncadd.com/policies.cfm. Accessed $9 / 10 / 03$.

National Highway Traffic Safety Administration \& the National Institute on Alcohol Abuse and Alcoholism. (1996). A Guide to Sentencing DUI Offenders. Washington, DC: DOT HS 808-365.

Neutel, C.I. (1995). Risk of traffic accident injury after a prescription for benzodiazepine. Annals of Epidemiology, 5(3), 239-244.

94 | Best Practices - Treatment and Rehabilitation for Driving While Impaired Offenders 
Nichols, J.L. (1990). Treatment versus deterrence. Alcohol Health and Research World, 14, 44-51.

Nickel, W.R. (1990a). A five-year follow-up of treatment for DWI recidivists in the Federal Republic of Germany. Alcohol, Drugs and Driving, 6, 119-132.

_ — _ (1990b). Programs for the rehabilitation and treatment of drinking-driving multiple offenders in the Federal Republic of Germany. In R.J. Wilson and R.E. Mann (Eds), Drinking and Driving, Advances in Research and Prevention, pp. 250-266. New York: The Guilford Press.

Nochajski, T.H. \& Miller, B.A. (1995). Training Manual for the Research Institute on Addictions Self-Inventory (RIASI). Buffalo, NY: Research Institute on Addictions.

Nochajski, T.H., Miller, B.A. \& Parks, K.A. (1994). Effectiveness of the RIASI for Screening of Convicted DWI Offenders. Buffalo, NY: Research Institute on Addictions.

Nochajski, T.H., Miller, B.A., Wieczorek, W.F. \& Parks, K.A. "The Utility of Non-Obvious Indicators for Screening of DWI Offenders". Paper presented at the annual meeting of the Research Society on Alcoholism, San Antonio, Texas, June 19-24,1993.

Parsons, M., Wnek, I. \& Huebert, K.M. (1993). A unique intervention program for repeat impaired driving offenders. Journal of Alcohol Drug Education, 39, 34-40.

Peck, R.C., Arstein-Kerslake, G.W. \& Helander, C.J. (1994). Psychometric and biographical correlates of drunk-driving recidivism and treatment program compliance. Journal of Studies on Alcohol, 55, 667-678.

Polacsek, M., Rogers, E.M., Woodall, W.G., Delaney, H., Wheeley, D. \& Rao, N. (2001). MADD victim impact panels and stages-of-changes in drunk-driving prevention. Journal of Studies on Alcohol, 62, 344-350.

Preusser, D.F., Ulmer, R.G. \& Adams, J.R. (1978). Driver record evaluation of a drinking driver rehabilitation program. Journal of Safety Research, 8, 98-105.

Price, E.J. (1993). Local Official Guide to Drunk Driving Prevention. Washington, DC: National League of Cities.

Quaye, K. \& Boase, P. "Is the Short-Term Administrative Suspension a Second Best but Necessary Alternative to Criminal Code Sanctions?" Paper presented at the 16th International Conference on Alcohol, Drugs and Traffic Safety - T2002, Montreal, Aug. 4-9, 2002.

Reis, R.E. (1982a). The Traffic Safety Effectiveness of Educational Counseling Programs for Multiple Offense Drunk Drivers. Washington, DC: National Highway Traffic Safety Administration.

DOT-HS-806-557. 
- - - (1982b). The Traffic Safety Effectiveness of Educational Counseling Programs for First Offense Drunk Drivers. Washington, DC: National Highway Traffic Safety Administration. DOT-HS-806-558.

Robins, L.N., Helzer, J.E., Ratcliff, K. \& Syfried, W. (1982). Validity of the Diagnostic Interview Schedule. Version II: DSM-III diagnosis. Psychological Medicine, 12, 855-870.

Ross, H.L. (1984). Deterring the Drinking Driver: Legal Policy and Social Control. Lexington, MA: D.C. Heath and Company.

Schmidt, W., Smart, R. \& Popham, R.E. (1963). The role of alcoholism in motor vehicle accidents. In J.D.J. Harvard (ed.) Alcohol and Road Traffic: Proceedings of the Third International Conference on Alcohol and Road Traffic. London: British Medical Association.

Selzer, M.L. (1971). The Michigan Alcoholism Screening Test: The quest for a new diagnostic instrument. American Journal of Psychiatry, 127, 89-94.

Shinar, D. \& Compton, R.P. (1995). Victim impact panels: Their impact on DUI recidivism. Alcohol, Drugs and Driving, 11, 73-87.

Shuggi, R., Chipperfield, B., Flam-Zalcman, R., Nochajski T.H. \& Mann, R.E. "Drinking-Driving Programs and Quality Control: Assessing Consistency of Program Implementation". Paper presented at the 14th International Conference on Alcohol, Drugs and Traffic Safety - T2002, Montreal, Aug. 4-9, 2002.

Single, E., Robson, L., Xie X. \& Rehm, J. (1996). The Costs of Substance Abuse in Canada. Ottawa: Canadian Centre on Substance Abuse.

Skinner, H.A. (1982). The Drug Abuse Screening Test. Addictive Behaviours, 7, 363-371.

Smart, R.G., \& Schmidt, W. (1961). Problem drinking as a factor in drinking-driving offences. Canadian Journal of Corrections, 3, 153-158.

Sobell, L.C. \& Sobell, M.B. (1992). Timeline follow-back: A technique for assessing self-reported alcohol consumption. In T.R. Litten and J. Allen (eds.), Measuring Alcohol Consumption:

Psychological and Biological Methods. Totowa, NJ: The Humana Press, Inc.

Spitzer, R.L., Williams, J.B., Gibbon, M. \& Forst, M.B. (1990). Structured Clinical Interview for DSM-III-R. Washington, DC: American Psychiatric Press.

Stoduto, G., Mann, R., Mitchell, B., Suurvali, H., Koski-Jannes, A., Room, R. \& Harrison, S. (1998). Existing Programs for Convicted Drinking Drivers in Canada. Toronto: Addiction Research Foundation. 
Stoduto, G., Vingilis, E., Kapur, B., Shen, W., McLellan, B. \& Liban, C. (1993). Alcohol and drug use among motor vehicle collision victims admitted to a regional trauma unit: Demographic, injury and crash characteristics. Accident Analysis and Prevention, 25(4), 411-420.

Tarter, R.E., Hegedus, A.M. (1991). The Drug Use Screening Inventory. Alcohol Health and Research World, 15, 65-75.

Taxman, F.S. \& Piquere, A. (1998). On preventing drunk driving recidivism: An examination of rehabilitation and punishment approaches. Journal of Criminal Justice, 26, 129-143.

The College of Family Physicians of Canada. (1994). Alcohol Risk Assessment and Intervention (ARAI): Resource Manual for Family Physicians. Mississauga, ON: College of Family Physicians of Canada.

Tornos, J. (1994). Rattfallan (The trap): Evaluation of an educational programme for imprisoned drunk drivers in Sweden. Recidivism rate within four years. Journal of Traffic Medicine, 2, 15-18.

Transport Canada (2002). Road Safety Vision 2010. Ottawa: Minister of Public Works and Government Services. Cat. No. T45-1/2001-1E

Van Whitlock, R. \& Lubin, B. (1998). Predicting outcome of court-ordered treatment for DWI offenders via the MAACL-R. Journal of Offender Rehabilitation, 28, 29-40.

Vingilis, E. (1983). Drinking drivers and alcoholics: Are they from the same population? In: R.G. Smart, F.B. Glaser, Y. Israel, H. Kalant, R.E. Popham, W. Schmidt. (eds.), Research Advances in Alcohol and Drug Problems, vol. VII, pp. 229-342. New York: Plenum Press.

Vingilis, E.R., Adlaf, E.M. \& Chung, L. (1981). The Oshawa impaired drivers program: An evaluation of a rehabilitation program. Journal of Criminology, 23, 372-374.

Voas, R.B. \& Fisher, D.A. (2001). Court procedures for handling intoxicated drivers. Alcohol Research and Health, 25, 32-42.

Walsh, G. \& Mann, R.E. (1999). On the high-road: Driving under the influence of cannabis in Ontario. Canadian Journal of Public Health, 90, 260-263.

Wells-Parker, E. \& Williams, M. (2002). "Enhancing the Effectiveness of Traditional Interventions with Drinking Drivers by Adding Brief Individual Intervention Components". Unpublished manuscript.

Wells-Parker, E., Anderson, B.J., McMillen, D.L. \& Landrum, J.W. (1988). Interactions among DUI offender characteristics and traditional intervention modalities: A long term recidivism followup. British Journal of Addiction, 84, 381-390. 
Wells-Parker, E., Bangert-Drowns, R., McMillen, R. \& Williams, M. (1995). Final results from a meta-analysis of remedial interventions with drink/drive offenders. Addiction, 9, 907-926.

Wells-Parker, E., Cosby, P.J. \& Landrum, J.W. (1986). A typology for drinking driving offenders: Methods for classification and policy implications. Accident Analysis and Prevention, 18, 443-453.

Wells-Parker, E., Keene, D.R., Spratke, K.L. \& Williams, M.T. (2000). Self-efficacy and motivation for controlling drinking and drinking/driving: An investigation of changes across a driving under the influence (DUI) intervention program. Addictive Behaviors, 25, 229-238.

Whitehead, P.C., Hylton, J. \& Markovsky, R. (1984). Alcoholics on the Road: Evaluation of an Impaired Driver Treatment Program. Regina: Saskatchewan Alcoholism Commission.

Wieczorek, W.F. \& Miller B.A. (1992). Preliminary typology designed for treatment matching of driving-while-intoxicated offenders. Journal of Consulting and Clinical Psychology, 60, 757-765.

Wieczorek, W.F., Miller, B.A. \& Nochajski, T.H. (1992). The limited utility of BAC for identifying alcohol-related problems among DWI offenders. Journal of Studies on Alcohol, 53, 415-419.

Wilson, R.J. (1991). Subtypes of DWIs and high-risk drivers. Alcohol, Drugs and Driving, 7, 1-12.

Winters, K. (1991). Manual for the Personal Experience Screening Questionnaire (PESQ). Los Angeles: Western Psychological Services.

Zelhart, P.F., Schurr, B.C. \& Brown, P.A. (1975). The drinking driver: Identification of high-risk alcoholics. In S. Israelstam and S. Lambert (eds.), Alcohol, Drugs and Traffic Safety: Proceedings of the 6th International Conference on Alcohol and Traffic Safety. Toronto: Addiction Research Foundation. 


\section{Appendix A: \\ Rating Scale for Recent Studies}

This scale used constructs and items from the meta-analysis project of Wells-Parker and colleagues (1995). However, given our more modest objectives, studies were not discriminated to the same degree. The aim was to indicate methodological rigour and thus the credibility of the reported results.

\section{Grouping strategies}

\begin{tabular}{|c|c|}
\hline $\begin{array}{l}\text { Random assignment with rigorous monitoring and no evidence of significant bias associated } \\
\text { with deviations from the randomization process and extensive evidence that groups did not } \\
\text { differ significantly on numerous pre-treatment variables (demographics, violation history, etc.) }\end{array}$ & 10 \\
\hline Random assignment but little descriptive information about monitoring or group equivalence & 9 \\
\hline Random assignment with low to moderate attrition $(<15 \%)$ unrelated to assignment & $8^{*}$ \\
\hline Random assignment with higher rates of attrition $(15 \%-30 \%)$ unrelated to assignment & $7^{*}$ \\
\hline Random assignment with evidence of non-adherence possibly related to assignment & $6^{*}$ \\
\hline Comparison group design with good evidence for group equivalence on key variables & 5 \\
\hline Comparison group design but less evidence that the groups were equivalent on key variables & $4^{*}$ \\
\hline Randomized assignment but poorly documented and indications of bias & $3^{*}$ \\
\hline Comparison group design but little evidence that the groups were equivalent on key variables & $2^{*}$ \\
\hline $\begin{array}{l}\text { Non-randomized design involving self-selected groups or randomized designs with high } \\
(>50 \%) \text { group attrition }\end{array}$ & $1^{*}$ \\
\hline Obvious and uncorrected biases & 0 \\
\hline \multicolumn{2}{|l|}{ Integrity of the intervention(s) } \\
\hline $\begin{array}{l}\text { Evidence that the intervention(s) and the experiences of the control or comparison groups } \\
\text { were as planned }\end{array}$ & $\begin{array}{l}\text { Good evidence }=2 \\
\text { Some slippage evi- } \\
\text { denced or suspected } \\
=1^{* \star} \\
\text { Major slippage or } \\
\text { not described }=0\end{array}$ \\
\hline Maximum score & 12 \\
\hline
\end{tabular}

* If evident or suspected biases were corrected using appropriate statistical methods.

** Including unplanned remediation or other interventions received by members of the control or comparison groups. 